\title{
SYNTHESIS, PHYSICOCHEMICAL CHARACTERIZATION AND ANTIBACTERIAL ACTIVITY OF NOVEL (BENZOYLAMINO)METHYL DERIVATIVES OF QUINOLONES
}

\author{
P. Breznica-Selmani ${ }^{1,2}$, K. Mladenovska ${ }^{1,3^{*}}$, G. Dräger ${ }^{4}$, B. Mikhova ${ }^{5}$, N. Panovski ${ }^{6}$, A. Kaftandzieva $^{6}$, \\ Z. Kavrakovski ${ }^{1}$, A. Hoxha ${ }^{7}$, N. Sheqerxhiu ${ }^{7}$, M. J. Pavlova ${ }^{6}$, E. Popovski ${ }^{3,8^{*}}$ \\ ${ }^{1}$ Institute of Pharmaceutical Chemistry, Faculty of Pharmacy, Ss. Cyril and Methodius University, \\ Mother Theresa 47, 1000 Skopje, Republic of Macedonia \\ ${ }^{2}$ Faculty of Medicine, University Hasan Prishtina, Mother Theresa n.n. 10000 Prishtina, Kosovo \\ ${ }^{3}$ Macedonian Academy of Science and Arts, Bul. Krste Misirkov 2, P.O. Box 428, \\ 1000 Skopje, Republic of Macedonia \\ ${ }^{4}$ Institute of Organic Chemistry, Leibniz Universität Hannover, D-30167, Hannover, Germany \\ ${ }^{5}$ Institute of Organic Chemistry with Centre of Phytochemistry, Bulgarian Academy of Sciences, \\ Acad. G. Bonchev 9, 1113 Sofia, Bulgaria \\ ${ }^{6}$ Institute of Microbiology and Parasitology, Faculty of Medicine, Ss. Cyril and Methodius University, \\ $50^{\text {th }}$ Division 6, 1000 Skopje, Republic of Macedonia \\ ${ }^{7}$ TreLab Quality Control Laboratory, Trepharm, Magjistralja Prishtina - Peje, \\ M9 12050 Fushe Kosovo, Kosovo \\ ${ }^{8}$ Institute of Chemistry, Faculty of Natural Sciences and Mathematics, University Ss. Cyril and Methodius, \\ Arhimedova 3, PO Box 162, 1000 Skopje, Republic of Macedonia \\ popovski.emil@gmail.com; krml@ff.ukim.edu.mk
}

Herein we report the synthesis of different derivatives of (fluoro)quinolones norfloxacin, ciprofloxacin and pipemidic acid, by incorporating (benzoylamino)methyl on the free nitrogen of the pyperazinyl moiety. The compounds were structurally characterized by 1D and 2D NMR, FTIR and highresolution mass spectroscopy. In addition, their physicochemical properties were a matter of interest to be correlated with their structure and antimicrobial activity in vitro. Their antimicrobial activities were screened against Gram-positive, Gram-negative bacteria and C. albicans. Higher distribution coefficients and consequently lower water solubility were determined for all synthesized compounds than the ones of the corresponding leading compounds. Inconsequential correlations between the lipophilicity of the compounds and MIC were observed, suggesting that passive diffusion is not the only mechanism for their penetration into bacterial cells. Further studies are needed to determine how substitutions in the (fluoro)quinolone moiety affect the primary target(s), substrate behavior in respect to bacterial transporters and overall bioavailability.

Keywords: (benzoylamino)methyl; quinolones; structure; physicochemical properties; antimicrobial activity

\section{СИНТЕЗА, ФИЗИЧКОХЕМИСКА КАРАКТЕРИЗАЦИЈА И АНТИБАКТЕРИСКА АКТИВНОСТ НА НОВИ (БЕНЗОИЛАМИНО)МЕТИЛНИ ДЕРИВАТИ НА ХИНОЛОНИ}

Во трудот е прикажана синтеза на различни деривати на (флуоро)хинолони со инкорпорирање на (бензоиламино)метилна група на слободниот азот од пиперазинскиот фрагмент кај норфлоксацинот, ципрофлоксацинот и пипемидинската киселина како водечки соединенија. Синтетизираните соединенија беа структурно карактеризирани со помош на 1D и 2D NMR, FTIR и масена спектрометрија со висока резолуција. Дополнително беа определени физичкохемиските особини на новосинтетизираните соединенија и корелирани со нивната структура и антимикро- 
бната активност in vitro. Антимикробната активност на новите соединенија беше испитувана на Gram-позитивни и Gram-негативни бактерии и на C. albicans. Сите новосинтетизирани соединенија покажаа повисок коефициент на распределба и соодветно пониска растворливост во вода во однос на водечките соединенија. Корелациите меѓу липофилноста на синтетизираните соединенија и минималната инхибиторна концентрација (MIC) не беа статистички значајни, што укажува на тоа дека пасивната дифузија не е единствениот механизам со кој тие пенетрираат во бактериските клетки. Потребни се понатамошни истражувања за да се испита како супституциите во (флуоро)хинолонското јадро влијаат врз примарната цел(и), супстратното однесување во однос на бактериските транспортери и севкупната биорасположливост.

Клучни зборови: (бензоиламино)метил; хинолони; структура; физичкохемиски својства; антимикробна активност

\section{INTRODUCTION}

Quinolones are synthetic antibiotics, representing a very fast growing group of antimicrobial agents. Since the discovery of the first one, 4quinolone (naphthyridine carboxylic acid), two major groups of quinolones have been developed: quinolones, identified by the presence of a nitrogen at position 8 , and naphthyridines, with a carbon and associated group at position 8 of the basic structure [1]. Their antibacterial activity, originating from the combination of bacterial cell penetration and DNA gyrase inhibitory activity, depends not only on the bicyclic heteroaromatic system combining the 1,4-dihydro-4-pyridine-3-carboxylic acid moiety and an aromatic ring, but also on the nature of the peripheral substituents and their spatial relationships. To date, over 10,000 quinolone molecules have been synthesized in attempts to provide many of the attributes of an ideal antibiotic: high potency, broad spectrum of activity, good bioavailability, convenient administration, high serum levels, large volume of distribution and potentially low-incidence of side effects.

With the introduction of fluoro substituent at C-6 in the bicyclic heteroaromatic pharmacophore, fluoroquinolones were created, with increased activity against the enzyme target DNA gyrase and penetration into the bacterial cell. The SAR studies revealed that the fluorine atom and the 1-alkyl, 1,4dihydro-4-oxo-quinolone-3-carboxylic acid skeleton of fluoroquinolone are responsible for potency, represented in binding not only to DNA gyrase, but also to type-II-isomerase and topoisomerase IV [2]. The quinolones were further enhanced by the addition of corresponding groups to the N-1, C-5 and $\mathrm{C}-7$ positions of their respective basic molecule. The addition of piperazine to $\mathrm{C}-7$ position (e.g. norfloxacin (NOR), ciprofloxacin (CIPRO), pipemidic acid (PIPEM)) improved activity against Gram-negative microorganisms, suggesting that the piperazine ring may play a role in inhibiting efflux mechanisms [3]. In addition to piperazine at the C-7 position, a cyclopropyl group was introduced to the $\mathrm{N}-1$ position as in CIPRO, resulting in considerably more potent and broader antibacterial activity than earlier fluoroquinolones [4]. Several $\mathrm{N}-4$ pyperazinyl derivatives of fluoroquinolones were also synthesized as broad spectrum antibacterials, such as benzenesulfonamidefluoroquinolones [5]. In addition, N-4 piperazinylaralkyl [6] or cephalosporin fluoroquinolone [7] derivatives were introduced showing to be effective as potential antimicrobial agents. The synthesis of some $\mathrm{N}$ Mannich bases was also reported, revealing compounds with better inhibitory activities against certain bacterial strains [8-10] and with anti-HIV and antifungal activity [11] in addition to antibacterial. $N$-Mannich bases are of particular interest in drug chemistry because of their potential to be used as prodrugs of $\mathrm{NH}$-acidic drugs containing amide, imide, ureide and amine moieties [12-17]. With respect to the amines, N-Mannich bases are useful when an increase in their lipophilicity is required. Lipophilicity of the quinolone amines as an important factor in the quinolones intestinal absorption is considered responsible for the poor relationship between in vivo and in vitro activity of quinolones [18]. In these compounds, N-Mannich base formation could suppress the $\mathrm{pKa}$, which means that an important proportion could remain unionized at physiological $\mathrm{pH}$, resulting in improved permeability and thus bioavailability.

In this paper, the synthesis of novel derivatives of leading (fluoro)quinolones NOR, CIPRO and PIPEM is presented. In addition to the structural characterization of these novel compounds, distribution behavior of these compounds between $n$-octanol and buffer solution (pH 7.4), solubility in water and $\mathrm{pH} 7.4$ and $\mathrm{p} K$ values were a matter of interest to be correlated with their structure and antimicrobial activity in vitro against Gram-positive and Gram-negative bacteria and C. albicans. 


\section{EXPERIMENTAL}

\subsection{Materials}

All of the chemicals and solvents used were purchased from commercial sources and were of the highest pure form. Melting points (uncorrected) were determined on a Mel-Temp II ${ }^{\circledR}$ in open glass capillaries. The compounds were structurally characterized by different spectroscopic techniques: The 1D $\left({ }^{1} \mathrm{H},{ }^{13} \mathrm{C}\{1 \mathrm{H}\}\right.$, DEPT) and 2D (COSY, HSQC, HMBC) NMR spectra were recorded on a Bruker Advance II+ $600 \mathrm{MHz}$ BioSpin GmbH (Rheinstetten, Germany) in DMSO- $d_{6}$ as solvent and tetramethylsilane as an internal standard. $\mathrm{CDCl}_{3}$ was added to $5 \mathrm{~d}$ to increase solubility. Chemical shifts are expressed in $\delta \mathrm{ppm}$, the coupling constants $J$ are expressed in hertz. Signals were abbreviated as s, singlet; d, doublet; t, triplet; m, multiplet and bs, broad singlet. Infrared spectra (Atr) were measured on a Perkin-Elmer System 2000 FT-IR. High-resolution mass spectra were made on an FT-ICR BrukerDaltonics Apex II on ESI-MS High resolution mode and Q-TOF premier (MICROMASS) spectrometer (ESI mode). The reaction monitoring and assessment of the purity of compounds were performed by TLC (Silica gel 60 F254 plates, Fluka, SigmaAldrich ChemieGmbh Munich, Germany), where the spots were visualized by exposure to a UV lamp at $\lambda_{\max } 254 \mathrm{~nm}$. Yields are of purified products and were not optimized. NOR (1), CIPRO (2) and PIPEM (3) were purchased from Fluka (SigmaAldrich ChemieGmbh Munich, Germany). [(Benzoylamino) methyl]triethylammonium salts 4a-d were prepared as [(3-chlorobenzoylamino) methyl] triethylammonium chloride, as reported in BreznicaSelmani et al. [19].

\subsection{General procedure for synthesis of (benzoylamino)methyl derivatives of NOR (5a-e)}

To separated mixtures of 1 ( 1 equiv.) and 4a-e (1.5 equiv) in $10 \mathrm{ml} \mathrm{DMSO}$, triethylamine (TEA) was added and allowed to stir for $3 \mathrm{~h}$ at 35 ${ }^{\circ} \mathrm{C}$. Afterwards, water was added until a white precipitate occurred. The precipitate was collected by filtration under pressure, washed with water and dried at room temperature until obtaining whiteyellow crystals. The products were re-crystallized by dissolving in DMSO and precipitation with water. For each product, the reactions were monitored with TLC (mobile phase $\mathrm{CHCl}_{3}: \mathrm{MeOH}, 3: 1$ ). Yields of purified products were from $82 \%$ to $96.4 \%$.

\subsubsection{Synthesis of 1-ethyl-6-fluoro-7-\{4[(benzo- \\ ylamino)methyl]piperazin-1-yl\}-4-oxo-1,4-dihyd- roquinoline-3-carboxylic acid (5a)}

Compound 5a was prepared using the above general procedure in $96 \%$ yield; $M_{p} 190-192{ }^{\circ} \mathrm{C}$; $\mathrm{M}_{\mathrm{w}} 452.48 \mathrm{~g} / \mathrm{mol}$; FT-IR-ATR: $3252.09 \mathrm{~cm}^{-1}$ and $3045.29 \mathrm{~cm}^{-1} v(\mathrm{~N}-\mathrm{H}) ; 2951.51 \mathrm{~cm}^{-1}$ and 2848.08 $\mathrm{cm}^{-1} v(\mathrm{C}-\mathrm{H}) ; 1616.62 \mathrm{~cm}^{-1}$ (Amide I); $1522.94 \mathrm{~cm}^{-1}$ (Amide II). ${ }^{1} \mathrm{H}$ NMR (600 MHz, DMSO-d $\left.{ }_{6}\right): \delta$ $1.38\left(\mathrm{t}, J=7.5 \mathrm{~Hz}, 3 \mathrm{H}, \mathrm{CH}_{3}\right), 2.75\left(\mathrm{~m}, 4 \mathrm{H}, \mathrm{H} 3{ }^{\prime}\right)$, $3.31\left(\mathrm{~m}, 4 \mathrm{H}, \mathrm{H} 2{ }^{\prime}\right), 4.23\left(\mathrm{~d}, 2 \mathrm{H}, J=7.0 \mathrm{~Hz}, \mathrm{CH}_{2} \mathrm{~N}\right)$, $4.57\left(\mathrm{q}, 2 \mathrm{H}, J=7.5 \mathrm{~Hz}, \mathrm{CH}_{3} \underline{\mathrm{CH}}_{2}\right), 7.20(\mathrm{~d}, 1 \mathrm{H}$, $\left.{ }^{4} J_{\mathrm{H}, \mathrm{F}}=7.5 \mathrm{~Hz}, \mathrm{H} 8\right), 7.40$ (m, 2H, ArH3, ArH5), 7.5 (m, $1 \mathrm{H}, \operatorname{ArH} 4), 7.80\left(\mathrm{~d}, 1 \mathrm{H},{ }^{3} J_{\mathrm{H}, \mathrm{F}}=13.5 \mathrm{~Hz}, \mathrm{H} 5\right)$, $7.90(\mathrm{~m}, 2 \mathrm{H}, \mathrm{ArH} 2, \mathrm{ArH} 6), 8.85$ (t, $1 \mathrm{H}, J=7.0$ $\mathrm{Hz}, \mathrm{NH}), 8.91$ (s, 1H, H2), 15.40 (br s, $1 \mathrm{H}, \mathrm{OH})$; ${ }^{13} \mathrm{C}$ NMR $\left(125 \mathrm{MHz}, \mathrm{DMSO}-\mathrm{d}_{6}\right): \delta 14.5\left(\mathrm{CH}_{3}\right)$, $49.5\left(2 \mathrm{C} 3^{\prime}\right), 49.51\left(2 \mathrm{C} 2^{\prime}\right), 60.5\left(\mathrm{CH}_{2} \mathrm{~N}\right), 106.0(\mathrm{~d}$, $\left.{ }^{3} J_{\mathrm{C}, \mathrm{F}}=3.0 \mathrm{~Hz}, \mathrm{C} 8\right), 107.4(\mathrm{C} 3), 111.3\left(\mathrm{~d},{ }^{2} J_{\mathrm{C}, \mathrm{F}}=\right.$ $23.0 \mathrm{~Hz}, \mathrm{C} 5), 119.3\left(\mathrm{~d},{ }^{3} J_{\mathrm{C}, \mathrm{F}}=9.5 \mathrm{~Hz}, \mathrm{C} 4 \mathrm{a}\right), 127.5$ (ArC2, ArC6), 128.5 (ArC3, ArC5), 131.6 (ArC4), 134.3 (ArC1), 137.4 (C8a), $145.7\left(\mathrm{~d},{ }^{2} J_{\mathrm{C}, \mathrm{F}}=10.0\right.$ $\mathrm{Hz}, \mathrm{C} 7), 153.8\left(\mathrm{~d},{ }^{1} J_{\mathrm{CF}}=250.0 \mathrm{~Hz}, \mathrm{C} 6\right), 166.4$ $(\mathrm{COOH}), 167.4(\mathrm{CONH}), 176.2\left(\mathrm{~d},{ }^{4} J_{\mathrm{C}, \mathrm{F}}=2.5 \mathrm{~Hz}\right.$, C4); Anal. Calc. for $\mathrm{C}_{24} \mathrm{H}_{25} \mathrm{FN}_{4} \mathrm{O}_{4}: \mathrm{C}, 63.71 ; \mathrm{H}$, 5.57; F, 4.20; N, 12.38; O, 14.14; HRMS (ESI, $\operatorname{pos})(\mathrm{m} / \mathrm{z}): 453.1932[\mathrm{M}+\mathrm{H}]^{+}, 475.1752 .[\mathrm{M}+\mathrm{Na}]^{+}$, $\mathrm{C}_{24} \mathrm{H}_{25} \mathrm{FN}_{4} \mathrm{O}_{4}$.

2.2.2. Synthesis of 1-ethyl-6-fluoro-7-\{4-[(4-methylbenzoylamino)methyl]piperazin-1-yl\}-4-oxo-1,4dihydroquinoline-3-carboxylic acid (5b)

Compound 5b was prepared using the above general procedure in $86 \%$ yield; $\mathrm{M}_{\mathrm{p}} 231^{\circ} \mathrm{C} ; \mathrm{M}_{\mathrm{w}}$ $466.5 \mathrm{~g} / \mathrm{mol}$; FT-IR-ATR: $3266.13 \mathrm{~cm}^{-1}$ and 3053.87 $\mathrm{cm}^{-1} v(\mathrm{~N}-\mathrm{H}) ; 2951.51 \mathrm{~cm}^{-1}$ and $2848.08 \mathrm{~cm}^{-1} v(\mathrm{C}-\mathrm{H})$; $1736.25 \mathrm{~cm}^{-1}$ (Amide I); $1645.76 \mathrm{~cm}^{-1}$ (Amide II). ${ }^{1} \mathrm{H}$ NMR (600 MHz, DMSO-d $\left.{ }_{6}\right): \delta 1.39$ (t, $3 \mathrm{H}, J=7.0$ $\left.\mathrm{Hz}, \mathrm{CH}_{2} \mathrm{CH}_{3}\right), 2.34\left(\mathrm{~s}, 3 \mathrm{H}, \mathrm{ArCH}_{3}\right), 2.71(\mathrm{~m}, 4 \mathrm{H}$, H3'), $3.31\left(\mathrm{~m}, 4 \mathrm{H}, \mathrm{H} 2^{\prime}\right), 4.22(\mathrm{t}, 2 \mathrm{H}, J=6.0 \mathrm{~Hz}$, $\left.\mathrm{CH}_{2} \mathrm{~N}\right), 4.56\left(\mathrm{q}, 2 \mathrm{H}, J=7.0 \mathrm{~Hz},-\mathrm{CH}_{2} \mathrm{CH}_{3}\right), 7.15(\mathrm{~d}$, $\left.1 \mathrm{H},{ }^{4} J_{\mathrm{H}, \mathrm{F}}=7.0 \mathrm{~Hz}, \mathrm{H} 8\right), 7.27(\mathrm{~d}, 2 \mathrm{H}, J=8.0 \mathrm{~Hz}$, ArH3, ArH5), 7.78 (d, 2H, $J=8.0 \mathrm{~Hz}, \mathrm{ArH} 2, \mathrm{ArH} 6)$, $7.88\left(\mathrm{~d}, 1 \mathrm{H},{ }^{3} \mathrm{~J}_{\mathrm{HF}}=13.5 \mathrm{~Hz}, \mathrm{H} 5\right), 8.92(\mathrm{~s}, 1 \mathrm{H}, \mathrm{H} 2)$, 15.40 (br s, $1 \mathrm{H}, \mathrm{OH}) ;{ }^{13} \mathrm{C}$ NMR $(125 \mathrm{MHz}$, DMSO$\left.\mathrm{d}_{6}\right): \delta 14.4\left(\mathrm{CH}_{2} \mathrm{CH}_{3}\right), 21.1\left(\mathrm{ArCH}_{3}\right), 49.46\left(2 \mathrm{C} 3^{\prime}\right)$, $49.50(2 \mathrm{C} 2), 60.4\left(\mathrm{CH}_{2} \mathrm{~N}\right), 107.1(\mathrm{C} 3), 111.2\left(\mathrm{~d},{ }^{2} J_{\mathrm{C}, \mathrm{F}}\right.$ $=23.5 \mathrm{~Hz}, \mathrm{C} 5), 119.3\left(\mathrm{~d},{ }^{3} J_{\mathrm{C}, \mathrm{F}}=7.5 \mathrm{~Hz}, \mathrm{C} 4\right), 127.4$ (ArC2,ArC6), 129.0 (ArC3, ArC5), 131.5 (ArC1), 137.3 (C8a), 141.4 (ArC4), $145.6\left(\mathrm{~d},{ }^{2} J_{\mathrm{C}, \mathrm{F}}=10.0 \mathrm{~Hz}\right.$, C7), $153.0\left(\mathrm{~d},{ }^{1} J_{\mathrm{C}, \mathrm{F}}=250.0 \mathrm{~Hz}, \mathrm{C} 6\right), 166.3(\mathrm{COOH})$, 167.2(CONH), $176.2\left(\mathrm{~d},{ }^{4} J_{\mathrm{C}, \mathrm{F}}=2.5 \mathrm{~Hz}, \mathrm{C} 4\right)$; Anal. Calc. for: $\mathrm{C}_{25} \mathrm{H}_{27} \mathrm{FN}_{4} \mathrm{O}_{4}$ : C, 64.37; H, 5.83; F, 4.07; 
$\mathrm{N}, 12.01 ; \mathrm{O}, 13.72$; HRMS (ESI, pos) $(\mathrm{m} / \mathrm{z})$ : $489.1908[\mathrm{M}+\mathrm{Na}]^{+}, \mathrm{C}_{25} \mathrm{H}_{27} \mathrm{FN}_{4} \mathrm{O}_{4}$.

\subsubsection{Synthesis of 1-ethyl-6-fluoro-7-\{4-[(3-me-} thylbenzoylamino)methyl]piperazin-1-yl\}-4-oxo-1,4dihydroquinoline-3-carboxylic acid (5c)

Compound $\mathbf{5 c}$ was prepared using the above general procedure in $94 \%$ yield; $\mathrm{M}_{\mathrm{p}} 199-200{ }^{\circ} \mathrm{C}$; $\mathrm{M}_{\mathrm{w}} 466.5 \mathrm{~g} / \mathrm{mol}$; FT-IR-ATR: $3258.55 \mathrm{~cm}^{-1}$ and $3048.47 \mathrm{~cm}^{-1} v(\mathrm{~N}-\mathrm{H}) ; 2915.96 \mathrm{~cm}^{-1}$ and 2848.08 $\mathrm{cm}^{-1} v(\mathrm{C}-\mathrm{H}) ; 1729.79 \mathrm{~cm}^{-1}$ (Amide I); $1645.76 \mathrm{~cm}^{-1}$ (Amide II). ${ }^{1} \mathrm{H}$ NMR (600 MHz, DMSO-d 6 ): $\delta$ $1.39\left(\mathrm{t}, 3 \mathrm{H}, J=7.0 \mathrm{~Hz}, \mathrm{CH}_{2} \underline{\mathrm{CH}}_{3}\right), 2.36(\mathrm{~s}, 3 \mathrm{H}$, $\left.\mathrm{ArCH}_{3}\right), 2.72$ (m, 4H, H3'), $3.32(\mathrm{~m}, 4 \mathrm{H}, \mathrm{H} 2$ '), 4.22 $\left(\mathrm{d}, 2 \mathrm{H}, J=7.0 \mathrm{~Hz}, \mathrm{CH}_{2} \mathrm{~N}\right), 4.56(\mathrm{q}, 2 \mathrm{H}, J=7.0 \mathrm{~Hz}$, $\left.\mathrm{C}_{2} \mathrm{CH}_{3}\right), 7.15\left(\mathrm{~d}, 1 \mathrm{H},{ }^{4} J_{\mathrm{H}, \mathrm{F}}=8.0 \mathrm{~Hz}, \mathrm{H} 8\right), 7.35-$ 7.37 (d, 2H, ArH3, ArH4), 7.67 (m, 1H, ArH6), 7.70 (br s, $1 \mathrm{H}$, ArH2), $7.88\left(\mathrm{~d}, 1 \mathrm{H},{ }^{3} J_{\mathrm{H}, \mathrm{F}}=13.0 \mathrm{~Hz}\right.$, $\mathrm{H} 5$ ), 8.93 (s, 1H, H2), 15.36 (br s, $1 \mathrm{H}, \mathrm{OH}) ;{ }^{13} \mathrm{C}$ NMR (125 MHz, DMSO-d $\left.)_{6}\right): \delta 14.4\left(\mathrm{CH}_{2} \mathrm{CH}_{3}\right)$, $21.0\left(\mathrm{ArCH}_{3}\right), 49.1\left(\mathrm{CH}_{2} \mathrm{CH}_{3}\right), 49.37,49.44,49.5$ (2C', 2C3'), $60.4\left(\mathrm{CH}_{2} \mathrm{~N}\right), 107.0(\mathrm{C} 3), 111.2(\mathrm{~d}$, $\left.{ }^{2} J_{\mathrm{C}, \mathrm{F}}=25.6 \mathrm{~Hz}, \mathrm{C} 5\right), 119.2\left(\mathrm{~d},{ }^{3} J_{\mathrm{C}, \mathrm{F}}=8.0 \mathrm{~Hz}, \mathrm{C} 4 \mathrm{a}\right)$, 127.9 (ArC2), 128.2 (ArC5), 131.9 (ArC4), 134.2 (ArC1), 137.2 (C8a), 137.6 (ArC3), $145.5\left(\mathrm{~d},{ }^{2} J_{\mathrm{C}, \mathrm{F}}\right.$ $=11.5 \mathrm{~Hz}, \mathrm{C} 7), 152.8\left(\mathrm{~d},{ }^{1} J_{\mathrm{C}, \mathrm{F}}=250.0 \mathrm{~Hz}, \mathrm{C} 6\right)$, $166.2(\mathrm{COOH}), 167.2(\mathrm{CONH}), 176.2\left(\mathrm{~d},{ }^{4} J_{\mathrm{C}, \mathrm{F}}=\right.$ $2.5 \mathrm{~Hz}, \mathrm{C} 4)$; Anal. Calc. for $\mathrm{C}_{25} \mathrm{H}_{27} \mathrm{FN}_{4} \mathrm{O}_{4}$ : C, 64.37; H, 5.83; F, 4.07; N, 12.01; O, 13.72; HRMS (ESI, pos) $(\mathrm{m} / \mathrm{z}): 489.1908 \quad[\mathrm{M}+\mathrm{Na}]^{+}, \quad \mathrm{C}_{25} \mathrm{H}_{27}$ $\mathrm{FN}_{4} \mathrm{O}_{4}$.

\subsubsection{Synthesis of 1-ethyl-6-fluoro-7-\{4-[(2-chlo-} robenzoylamino)methyl]piperazin-1-yl\}-4-oxo-1,4 dihydroquinoline-3-carboxylic acid (5d)

Compound 5d was prepared using the above general procedure in $91 \%$ yield; $\mathrm{M}_{\mathrm{p}} 150-152{ }^{\circ} \mathrm{C}$; $\mathrm{M}_{\mathrm{w}} 486.92 \mathrm{~g} / \mathrm{mol}$; FT-IR-ATR: $3271.48 \mathrm{~cm}^{-1}$ and $3045.29 \mathrm{~cm}^{-1} v(\mathrm{~N}-\mathrm{H}) ; 2957.97 \mathrm{~cm}^{-1}$ and 2844.8 $\mathrm{cm}^{-1} v(\mathrm{C}-\mathrm{H}) ; 1729.79 \mathrm{~cm}^{-1}$ (Amide I); $1616.67 \mathrm{~cm}^{-1}$ (Amide II). ${ }^{1} \mathrm{H}$ NMR (600 MHz, DMSO- $\mathrm{d}_{6} / \mathrm{CDCl}_{3}$ ca. 4:1): $\delta 1.43\left(\mathrm{t}, 3 \mathrm{H}, J=7.5 \mathrm{~Hz}, \mathrm{CH}_{3}\right), 2.79(\mathrm{~m}$, $4 \mathrm{H}, \mathrm{H}^{\prime}$ ), 3.33 (m, 4H, H2'), 4.22 ( d, 2H, $J=7.0$ $\mathrm{Hz}, \mathrm{CH}_{2} \mathrm{~N}$ ), 4.56 (q, $2 \mathrm{H}, J=7.0 \mathrm{~Hz}, \mathrm{CH}_{3} \mathrm{CH}_{2}$ ), $7.12\left(\mathrm{~d}, 1 \mathrm{H},{ }^{3} J_{\mathrm{H}, \mathrm{F}}=7.9 \mathrm{~Hz}, \mathrm{H} 8\right), 7.36(\mathrm{ddd}, 1 \mathrm{H}, J=$ 7.5, 7.5, $1.5 \mathrm{~Hz}, \mathrm{ArH} 4), 7.39-7.45$ (3H, ArH3, ArH5, ArH6), $7.87\left(\mathrm{~d}, 1 \mathrm{H},{ }^{3} J_{\mathrm{H}, \mathrm{F}}=13.2 \mathrm{~Hz}, \mathrm{H} 5\right)$, $8.82(\mathrm{t}, 1 \mathrm{H}, J=7.5 \mathrm{~Hz}, \mathrm{NH}), 8.91(\mathrm{~s}, 1 \mathrm{H}, \mathrm{H} 2)$, 15.36 (br s, $1 \mathrm{H}, \mathrm{OH}) ;{ }^{13} \mathrm{C}$ NMR $(125 \mathrm{MHz}$, DMSO-d ${ }_{6} / \mathrm{CDCl} 3$ ca. $\left.1: 4\right): \delta 14.3\left(\mathrm{CH}_{3}\right), 49.0$, 49.1, $49.4\left(2 \mathrm{C} 2 ', 2 \mathrm{C} 3^{\prime}\right), 60.2\left(\mathrm{CH}_{2} \mathrm{~N}\right), 105.4(\mathrm{~d}$, $\left.{ }^{3} J_{\mathrm{C}, \mathrm{F}}=3.5 \mathrm{~Hz}, \mathrm{C} 8\right), 107.1(\mathrm{C} 3), 111.2\left(\mathrm{~d},{ }^{2} J_{\mathrm{C}, \mathrm{F}}=\right.$ $23.0 \mathrm{~Hz}, \mathrm{C} 5), 119.2\left(\mathrm{~d},{ }^{3} J_{\mathrm{C}, \mathrm{F}}=8.0 \mathrm{~Hz}, \mathrm{C} 4 \mathrm{a}\right), 127.1$
(ArC3), 128.7 (ArC6), 130.7 (ArC4), 137.2 (ArC2), 137.1 (C8a), 145.5 (ArC1), 148.5 (C2), $145.5\left(\mathrm{~d},{ }^{2} J_{\mathrm{C}, \mathrm{F}}=10.0 \mathrm{~Hz}, \mathrm{C} 7\right), 152.9\left(\mathrm{~d},{ }^{1} J_{\mathrm{C}, \mathrm{F}}=\right.$ $251.0 \mathrm{~Hz}, \mathrm{C} 6), 166.2(\mathrm{COOH}), 167.3(\mathrm{CONH})$, $176.2\left(\mathrm{~d},{ }^{4} J_{\mathrm{C}, \mathrm{F}}=2.5 \mathrm{~Hz}, \mathrm{C} 4\right)$; Anal. Calc. for $\mathrm{C}_{24} \mathrm{H}_{24}$ $\mathrm{ClFN}_{4} \mathrm{O}_{4}: \mathrm{C}, 59.2 ; \mathrm{H}, 4.97 ; \mathrm{Cl}, 7.28 ; \mathrm{F}, 3.90 ; \mathrm{N}$, 11.51; O, 13.14; TOF-MS-ES ${ }^{+}(\mathrm{m} / \mathrm{z}): 487.1550$ $[\mathrm{M}+\mathrm{H}]^{+}, 509.1430[\mathrm{M}+\mathrm{Na}]^{+}, \mathrm{C}_{24} \mathrm{H}_{24} \mathrm{ClFN}_{4} \mathrm{O}_{4}$.

\subsubsection{Synthesis of 1-ethyl-6-fluoro-7-\{4-[(3-chlo- robenzoylamino)methyl]piperazin-1-yl\}-4-oxo-1,4- dihydroquinoline-3-carboxylic acid (5e)}

Compound 5e was prepared using the above general procedure in $92 \%$ yield; $\mathrm{M}_{\mathrm{p}} 199-200{ }^{\circ} \mathrm{C}$; $M_{\mathrm{w}} 486.92 \mathrm{~g} / \mathrm{mol}$; FT-IR-ATR: $3266.15 \mathrm{~cm}^{-1}$ and $3051.93 \mathrm{~cm}^{-1} v(\mathrm{~N}-\mathrm{H}) ; 2954.74 \mathrm{~cm}^{-1}$ and 2848,02 $\mathrm{cm}^{-1} v(\mathrm{C}-\mathrm{H}) ; 1733.02 \mathrm{~cm}^{-1}$ (Amide I); $1629,6 \mathrm{~cm}^{-1}$ (Amide II). ${ }^{1} \mathrm{H}$ NMR (600 MHz, DMSO-d $\left.{ }_{6}\right): \delta$ $1.38\left(\mathrm{t}, 3 \mathrm{H}, J=7.5 \mathrm{~Hz}, \mathrm{CH}_{3}\right), 2.72\left(\mathrm{~m}, 4 \mathrm{H}, \mathrm{H} 3{ }^{\prime}\right)$, $\left.3.31(\mathrm{~m}, 4 \mathrm{H}, \mathrm{H} 2)^{\prime}\right), 4.33\left(\mathrm{~d}, 2 \mathrm{H}, J=7.0 \mathrm{~Hz}, \mathrm{CH}_{2} \mathrm{~N}\right)$, 4.56 (q, $\left.2 \mathrm{H}, J=7.0 \mathrm{~Hz}, \mathrm{C}_{2} \mathrm{CH}_{3}\right), 7.20(\mathrm{~d}, 1 \mathrm{H}$, $\left.{ }^{4} J_{\mathrm{H}, \mathrm{F}}=7.2 \mathrm{~Hz}, \mathrm{H} 8\right), 7.51(\mathrm{dd}, 1 \mathrm{H}, J=7.5 \mathrm{~Hz}$, ArH5), 7.61 (dd, 1H, $J=7.5,1.5 \mathrm{~Hz}, \mathrm{ArH} 4), 7.84$ (br d, $1 \mathrm{H}, J=7.5 \mathrm{~Hz}$, ArH6), $7.85\left(\mathrm{~d}, 1 \mathrm{H},{ }^{3} J_{\mathrm{H}, \mathrm{F}}=\right.$ $13.5 \mathrm{~Hz}, \mathrm{H} 5), 7.92(\mathrm{dd}, 1 \mathrm{H}, J=1.5 \mathrm{~Hz}, \mathrm{ArH} 2)$, $8.91(\mathrm{~s}, 1 \mathrm{H}, \mathrm{H} 2), 8.98$ (t, $1 \mathrm{H}, J=7.5 \mathrm{~Hz}, \mathrm{NH}$ ), 15.10 (br s, $1 \mathrm{H} \mathrm{OH}$ ); ${ }^{13} \mathrm{C}$ NMR (125 MHz, DMSO$\left.\mathrm{d}_{6}\right): \delta 14.4\left(\mathrm{CH}_{3}\right), 49.1\left(\mathrm{CH}_{2} \mathrm{CH}_{3}\right), 49.38,49.46$, $49.49\left(2 \mathrm{C}^{\prime}, 2 \mathrm{C} 3{ }^{\prime}\right), 60.6\left(\mathrm{CH}_{2} \mathrm{~N}\right), 105.9\left(\mathrm{~d},{ }^{3} J_{\mathrm{C}, \mathrm{F}}=\right.$ $3.0 \mathrm{~Hz}, \mathrm{C} 8), 107.2(\mathrm{C} 3), 111.2\left({ }^{2} J_{\mathrm{C}, \mathrm{F}}=23.0 \mathrm{~Hz}\right.$, C5), $119.2\left({ }^{3} J_{\mathrm{C}, \mathrm{F}}=7.7 \mathrm{~Hz}, \mathrm{C} 4 \mathrm{a}\right), 126.4$ (ArC6), 127.2 (ArC2), 131.3 (ArC4), 133.3 (ArC3), 136.2 (ArC1), $137.2(\mathrm{C} 8 \mathrm{a}), 145.6\left(\mathrm{~d},{ }^{2} J_{\mathrm{C}, \mathrm{F}}=10.0 \mathrm{~Hz}, \mathrm{C} 7\right)$, $152.9\left({ }^{1} J_{\mathrm{C}, \mathrm{F}}=251.0 \mathrm{~Hz}, \mathrm{C} 6\right), 166.2(\mathrm{CONH}), 165.8$ $(\mathrm{COOH}), 176.2\left(\mathrm{~d},{ }^{4} J_{\mathrm{C}, \mathrm{F}}=2.5 \mathrm{~Hz}, \mathrm{C} 4\right)$. Anal. Calc. for: $\mathrm{C}_{24} \mathrm{H}_{24} \mathrm{ClFN}_{4} \mathrm{O}_{4} \mathrm{C}, 59.2 ; \mathrm{H}, 4.97 ; \mathrm{Cl}, 7.28 ; \mathrm{F}$, 3.90; N, 11.51; O 13.14; HRMS (ESI, pos) $(\mathrm{m} / z)$ : $509.1362[\mathrm{M}+\mathrm{Na}]^{+}, \mathrm{C}_{24} \mathrm{H}_{24} \mathrm{ClFN}_{4} \mathrm{O}_{4}$.

\subsection{General procedure for synthesis of (benzoylamino)methyl derivatives of CIPRO $(\mathbf{6 a}-d)$}

At the beginning, a mixture of 2 (1 equiv.) in $10 \mathrm{ml}$ of water and 4a-e (1.5 equiv.) separately in $10 \mathrm{ml}$ of water was prepared. To the mixture, TEA was added until $\mathrm{pH} 11$ was achieved, followed by stirring $24 \mathrm{~h}$ at $35^{\circ} \mathrm{C}$. Afterwards, the reaction mixture was extracted with dichloromethane $(\mathrm{DCM})(3 \times 25 \mathrm{ml})$. The DCM extract was collected, washed successively with water brine, dried over $\mathrm{Na}_{2} \mathrm{SO}_{4}$, filtered and concentrated in vacuo to give a white solid, which was purified by dissolving in DMSO and precipitation with water. For each product, the reactions were monitored with 
TLC (mobile phase $\mathrm{CHCl}_{3}: \mathrm{MeOH}, 3: 1$ ). Yields of purified products were from $71.7 \%$ to $98.2 \%$.

\subsubsection{Synthesis of 1-cyclopropyl-6-fluoro-7-\{4-}

[(benzoylamino)methyl]piperazin-1-yl\}-4-oxo-1,4dihydroquinoline-3-carboxylic acid (6a)

Compound 6a was prepared using the above general procedure in $96.4 \%$ yield; $\mathrm{M}_{\mathrm{p}} 212-214{ }^{\circ} \mathrm{C}$; $\mathrm{M}_{\mathrm{w}} 464.49 \mathrm{~g} / \mathrm{mol}$; FT-IR-ATR: $3433.6 \mathrm{~cm}^{-1}$ and $3387.1 \mathrm{~cm}^{-1} v(\mathrm{~N}-\mathrm{H}) ; 2989.37 \mathrm{~cm}^{-1}$ and $2831.04 \mathrm{~cm}^{-1}$ $v(\mathrm{C}-\mathrm{H}) ; 1717.06 \mathrm{~cm}^{-1}$ (Amide I); $1661.17 \mathrm{~cm}^{-1}(\mathrm{Am}-$ ide II). ${ }^{1} \mathrm{H}$ NMR $\left(600 \mathrm{MHz}, \mathrm{DMSO}-\mathrm{d}_{6}\right): \delta 1.10(\mathrm{~m}$, $\left.2 \mathrm{H}, \mathrm{CH}_{2}\right), 1.32\left(\mathrm{~m}, 2 \mathrm{H}, \mathrm{CH}_{2}\right), 2.79\left(\mathrm{~m}, 4 \mathrm{H}, \mathrm{H}^{\prime}\right)$, $3.29\left(\mathrm{~m}, 4 \mathrm{H}, \mathrm{H} 2\right.$ '), $4.29\left(\mathrm{~d}, 2 \mathrm{H}, J=6.0 \mathrm{~Hz}, \mathrm{CH}_{2} \mathrm{~N}\right)$, $3.55(\mathrm{~m}, 1 \mathrm{H}, \mathrm{CH}), 7.46\left(\mathrm{~d}, 1 \mathrm{H},{ }^{4} J_{\mathrm{H}, \mathrm{F}}=7.6 \mathrm{~Hz}\right.$, H8), 7.35 (dd, $2 \mathrm{H}, J=8.0 \mathrm{~Hz}, \mathrm{ArH} 3, \mathrm{ArH} 5), 7.42$ (dd, $1 \mathrm{H}, J=8.0 \mathrm{~Hz}$, ArH4), 7.81 (d, $2 \mathrm{H}, J=8.0$ $\mathrm{Hz}, \mathrm{ArH} 2$, ArH6), $7.85\left(\mathrm{~d}, 1 \mathrm{H},{ }^{3} \mathrm{~J}_{\mathrm{H}, \mathrm{F}}=13.2 \mathrm{~Hz}, \mathrm{H} 5\right)$, $8.23(\mathrm{t}, 1 \mathrm{H}, J=6.5 \mathrm{~Hz}, \mathrm{NH}), 8.66(\mathrm{~s}, 1 \mathrm{H}, \mathrm{H} 2)$, 15.24 (br s, $1 \mathrm{H}, \mathrm{OH}) ;{ }^{13} \mathrm{C}-\mathrm{NMR}(125 \mathrm{MHz}$, DMSO-d 6$): \delta 7.6\left(2 \mathrm{CH}_{2}\right), 35.1(\mathrm{CH}), 49.2(2 \mathrm{C} 2$ ', 2C3'), $60.6\left(\mathrm{CH}_{2} \mathrm{~N}\right), 104.8\left(\mathrm{~d},{ }^{4} J_{\mathrm{C}, \mathrm{F}}=4.0 \mathrm{~Hz}, \mathrm{C} 8\right)$, $111.5\left({ }^{2} J_{\mathrm{C}, \mathrm{F}}=25.0 \mathrm{~Hz}, \mathrm{C} 5\right), 119.0\left(\mathrm{~d},{ }^{3} J_{\mathrm{C}, \mathrm{F}}=8.0 \mathrm{~Hz}\right.$, C4a), 127.0 (ArC2, ArC6), 127.9 (ArC4), 131.1 (ArC3, ArC5), 133.9 (ArC1), 138.8 (C8a), 145.5 $\left({ }^{2} J_{\mathrm{C}, \mathrm{F}}=10.5 \mathrm{~Hz}, \mathrm{C} 7\right), 147.1(\mathrm{C} 2), 153.0(\mathrm{~d}$, $\left.{ }^{1} J_{\mathrm{C}, \mathrm{F}}=250.0, \mathrm{C} 6\right), 166.7(\mathrm{COOH}), 168.1(\mathrm{CONH})$, $176.6\left(\mathrm{~d},{ }^{4} J_{\mathrm{C}, \mathrm{F}}=2.5 \mathrm{~Hz}, \mathrm{C} 4\right)$; Anal. Calc. for: $\mathrm{C}_{25} \mathrm{H}_{25} \mathrm{FN}_{4} \mathrm{O}_{4}$ : C, 64.64; H, 5.42; F 4.09; N, 12.06; O, 13.78; HRMS (ESI, pos) $(\mathrm{m} / \mathrm{z}): 465.1932$ $[\mathrm{M}+\mathrm{H}]^{+}, 487.1752[\mathrm{M}+\mathrm{Na}]^{+}, \mathrm{C}_{25} \mathrm{H}_{25} \mathrm{FN}_{4} \mathrm{O}_{4}$.

\subsubsection{Synthesis of 1-cyclopropyl-6-fluoro-7-\{4-} [(4-methylbenzoylamino)methyl]piperazin-1-yl\}-4oxo-1,4-dihydroquinoline-3-carboxylic acid $(\mathbf{6 b})$

Compound $\mathbf{6 b}$ was prepared using the above general procedure in $71.7 \%$ yield; $\mathrm{M}_{\mathrm{p}} 218-219^{\circ} \mathrm{C}$; $\mathrm{M}_{\mathrm{w}} 478.52 \mathrm{~g} / \mathrm{mol}$; FT-IR-ATR: $3275.6 \mathrm{~cm}^{-1}$ and $3036.02 \mathrm{~cm}^{-1} v(\mathrm{~N}-\mathrm{H}) ; 2954.99 \mathrm{~cm}^{-1}$ and 2841.54 $\mathrm{cm}^{-1} v(\mathrm{C}-\mathrm{H}) ; 1736.25 \mathrm{~cm}^{-1}$ (Amide I); $1626.05 \mathrm{~cm}^{-1}$ (Amide II). ${ }^{1} \mathrm{H}$ NMR $\left(600 \mathrm{MHz}\right.$, DMSO-d $\left.{ }_{6}\right): \delta$ $1.15\left(\mathrm{~m}, 2 \mathrm{H}, \mathrm{CH}_{2}\right), 1.30\left(\mathrm{~m}, 2 \mathrm{H}, \mathrm{CH}_{2}\right), 2,35(\mathrm{~s}, 3 \mathrm{H}$, $\left.\mathrm{CH}_{3}\right), 2.72\left(\mathrm{~m}, 4 \mathrm{H}, \mathrm{H} 3\right.$ '), $3.32\left(\mathrm{~m}, 4 \mathrm{H}, \mathrm{H} 2{ }^{\prime}\right), 4.21$ $\left(\mathrm{d}, 2 \mathrm{H}, J=6.0 \mathrm{~Hz}, \mathrm{NCH}_{2}\right), 3.81(\mathrm{~m}, 1 \mathrm{H}, \mathrm{CH}), 7.55$ $\left(\mathrm{d}, 1 \mathrm{H},{ }^{4} J_{\mathrm{H}-\mathrm{F}}=7.5 \mathrm{~Hz}, \mathrm{H} 8\right), 7.27(\mathrm{~d}, 2 \mathrm{H}, J=8.0 \mathrm{~Hz}$, ArH3, ArH5), $7.80(\mathrm{~d}, 2 \mathrm{H}, J=8.0 \mathrm{~Hz}, \mathrm{ArH} 2$, ArH6), $7.88\left(\mathrm{~d}, 1 \mathrm{H},{ }^{3} J_{\mathrm{HF}}=13.5 \mathrm{~Hz}, \mathrm{H} 5\right), 8.80(\mathrm{t}$, $1 \mathrm{H}, J=6.5 \mathrm{~Hz}, \mathrm{NH}), 8.65$ (s, 1H, H2), 15.24 (br s, $1 \mathrm{H}, \mathrm{OH}) ;{ }^{13} \mathrm{C}$ NMR $\left(125 \mathrm{MHz}, \mathrm{DMSO}-\mathrm{d}_{6}\right): \delta 7.6$ $\left(2 \mathrm{CH}_{2}\right), 21.0\left(\mathrm{CH}_{3}\right), 35.9(\mathrm{CH}), 49.4\left(2 \mathrm{C}^{\prime}, 2 \mathrm{C} 3^{\prime}\right)$, $60.4\left(\mathrm{CH}_{2} \mathrm{~N}\right), 106.5\left(\mathrm{~d},{ }^{3} J_{\mathrm{C}, \mathrm{F}}=3.5 \mathrm{~Hz}, \mathrm{C} 8\right)$, 106.7(C3), $111.5\left(\mathrm{~d},{ }^{2} J_{\mathrm{C}, \mathrm{F}}=23.0 \mathrm{~Hz}, \mathrm{C} 5\right), 118.6(\mathrm{~d}$, $\left.{ }^{3} J_{\mathrm{C}, \mathrm{F}}=9.0 \mathrm{~Hz}, \mathrm{C} 4 \mathrm{a}\right), 127.4(\mathrm{ArC} 2, \mathrm{ArC} 6), 128.4$
(ArC3, ArC5), 131.4 (ArC1), 139.3 (C8a), 141.4 (ArC4), $145.3\left({ }^{2} J_{\mathrm{C}, \mathrm{F}}=10.0 \mathrm{~Hz}, \mathrm{C} 7\right), 153.0\left(\mathrm{~d},{ }^{1} J_{\mathrm{C}, \mathrm{F}}\right.$ $=250.0 \mathrm{~Hz}, \mathrm{C} 6), 166.1(\mathrm{COOH}), 167.1(\mathrm{CONH})$, $176.4\left(\mathrm{~d},{ }^{4} J_{\mathrm{C}, \mathrm{F}}=2.5 \mathrm{~Hz}, \mathrm{C} 4\right)$; Anal. Calc. for: $\mathrm{C}_{26} \mathrm{H}_{27}$ $\mathrm{FN}_{4} \mathrm{O}_{4}$ : C, 65.26; H, 5.69; F, 3.97; N, 11.71; O, 13.37; HRMS (ESI, pos) $(\mathrm{m} / \mathrm{z}): 501.1908$ $[\mathrm{M}+\mathrm{Na}]^{+}, \mathrm{C}_{26} \mathrm{H}_{27} \mathrm{FN}_{4} \mathrm{O}_{4}$.

\subsubsection{Synthesis of 1-cyclopropyl-6-fluoro-7-\{4-} [(3-methylbenzoylamino)methyl]piperazin-1-yl]-4oxo-1,4-dihydroquinoline-3-carboxylic acid (6c)

Compound $\mathbf{6 c}$ was prepared using the above general procedure in $87.2 \%$ yield; $\mathrm{M}_{\mathrm{p}} 212-214{ }^{\circ} \mathrm{C}$; $\mathrm{M}_{\mathrm{w}} 478.52 \mathrm{~g} / \mathrm{mol}$; FT-IR-ATR: $3298.57 \mathrm{~cm}^{-1}$ and $3010.09 \mathrm{~cm}^{-1} v(\mathrm{~N}-\mathrm{H}) ; 2948.5 \mathrm{~cm}^{-1}$ and 2835.06 $\mathrm{cm}^{-1} v(\mathrm{C}-\mathrm{H}) ; 1716.6 \mathrm{~cm}^{-1}$ (Amide I); $1626.05 \mathrm{~cm}^{-1}$ (Amide II). ${ }^{1} \mathrm{H}$ NMR (600 MHz, DMSO-d 6 ): $\delta 1.16$ $\left(\mathrm{m}, 2 \mathrm{H}, \mathrm{CH}_{2}\right), 1.30\left(\mathrm{~m}, 2 \mathrm{H}, \mathrm{CH}_{2}\right), 2.35(\mathrm{~s}, 3 \mathrm{H}$, $\left.\mathrm{CH}_{3}\right), 2.72$ (m, 4H, H3'), 3.32 (m, 4H, H2'), 4.21 $\left(\mathrm{d}, 2 \mathrm{H}, J=6.0 \mathrm{~Hz}, \mathrm{NCH}_{2}\right), 3.82(\mathrm{~m}, 1 \mathrm{H}, \mathrm{CH})$, 7.35-7.37 (m, 2H, ArH4, ArH5), $7.56\left(\mathrm{~d}, 1 \mathrm{H},{ }^{4} J_{\mathrm{H}, \mathrm{F}}\right.$ $=7.5 \mathrm{~Hz}, \mathrm{H} 8), 7.67$ (br s, $1 \mathrm{H}, \mathrm{ArH} 2), 7.68(\mathrm{~m}, 1 \mathrm{H}$, ArH5), $7.90\left(\mathrm{~d}, 1 \mathrm{H},{ }^{3} J_{\mathrm{H}, \mathrm{F}}=13.5 \mathrm{~Hz}, \mathrm{H} 5\right), 8.65(\mathrm{~s}$, $1 \mathrm{H}, \mathrm{H} 2), 8.82$ (t, 1H, $J=6.5, \mathrm{~Hz}, \mathrm{NH}), 15.24$ (br s, $1 \mathrm{H}, \mathrm{OH}) ;{ }^{13} \mathrm{C}$ NMR (125 MHz, DMSO-d 6 ): $\delta 7.6$ $\left(2 \mathrm{CH}_{2}\right), 21.0\left(\mathrm{CH}_{3}\right), 35.9\left(\mathrm{CH}_{2}\right), 49.35,49.39$, $49.41\left(2 \mathrm{C} 2 ', 2 \mathrm{C}^{\prime}\right), 60.4\left(\mathrm{CH}_{2} \mathrm{~N}\right), 106.7(\mathrm{C} 3), 111.5$ $\left(\mathrm{d},{ }^{2} J_{\mathrm{C}, \mathrm{F}}=23.0 \mathrm{~Hz}, \mathrm{C} 5\right), 118.6\left(\mathrm{~d},{ }^{3} J_{\mathrm{C}, \mathrm{F}}=9.0 \mathrm{~Hz}\right.$, C4a), 124.5 (ArC6), 127.9 (ArC2), 128.2 ( ArC5), 131.9(ArC4), 134.3(ArC1), 137.6 (ArC3), 139.3 $(\mathrm{C} 8 \mathrm{a}), 153.0\left(\mathrm{~d},{ }^{1} J_{\mathrm{C}, \mathrm{F}}=250.0 \mathrm{~Hz}, \mathrm{C} 6\right), 145.3\left({ }^{2} J_{\mathrm{C}, \mathrm{F}}\right.$ $=10.0 \mathrm{~Hz}, \mathrm{C} 7), 166.0(\mathrm{COOH}), 167.1(\mathrm{CONH})$, $176.4\left(\mathrm{~d},{ }^{4} J_{\mathrm{C}, \mathrm{F}}=2.5 \mathrm{~Hz}, \mathrm{C} 4\right)$; Anal. Calc. for: $\mathrm{C}_{26} \mathrm{H}_{27}$ $\mathrm{FN}_{4} \mathrm{O}_{4}: \mathrm{C}, 65.26 ; \mathrm{H}, 5.69 ; \mathrm{F}, 3.97 ; \mathrm{N}, 11.71 ; \mathrm{O}$, 13.37; HRMS (ESI, pos) $(\mathrm{m} / \mathrm{z})$ : $479.2089[\mathrm{M}+\mathrm{H}]^{+}$, $501.1908[\mathrm{M}+\mathrm{Na}]^{+}, \mathrm{C}_{26} \mathrm{H}_{27} \mathrm{FN}_{4} \mathrm{O}_{4}$.

\subsubsection{Synthesis of 1-cyclopropyl-6-fluoro-7-\{4-}

[(2-chlorobenzoylamino)methyl]piperazin-1-yl\}-4oxo-1,4-dihydroquinoline-3-carboxylic acid (6d)

Compound 6d was prepared using the above general procedure in $98.2 \%$ yield; $\mathrm{M}_{\mathrm{p}} 149{ }^{\circ} \mathrm{C} ; \mathrm{M}_{\mathrm{w}}$ $498.93 \mathrm{~g} / \mathrm{mol}$; FT-IR-ATR: $3541.82 \mathrm{~cm}^{-1}$ and $3254.27 \mathrm{~cm}^{-1} v(\mathrm{~N}-\mathrm{H}) ; 2925.19 \mathrm{~cm}^{-1}$ and 2864.48 $\mathrm{cm}^{-1} v(\mathrm{C}-\mathrm{H}) ; 1717.47 \mathrm{~cm}^{-1}$ (Amide I); $1663.15 \mathrm{~cm}^{-1}$ (Amide II). ${ }^{1} \mathrm{H}$ NMR (600 MHz, DMSO-d 6 ): $\delta 1.14$ $\left(\mathrm{m}, 2 \mathrm{H}, \mathrm{CH}_{2}\right), 1.28\left(\mathrm{~m}, 2 \mathrm{H}, \mathrm{CH}_{2}\right), 2.75(\mathrm{~m}, 4 \mathrm{H}$, H3'), 3.31 (m, 4H, H2'), 3.77 (m, 1H, CH), 4.17 (d, $\left.2 \mathrm{H}, J=6.0 \mathrm{~Hz}, \mathrm{NCH}_{2}\right), 7.39(\mathrm{dd}, 2 \mathrm{H}, J=8.0 \mathrm{~Hz}$, ArH4), 7.42-7.52 (3H, ArH3, ArH5, ArH6), 7.53 $\left(\mathrm{d}, 1 \mathrm{H},{ }^{4} J_{\mathrm{H}, \mathrm{F}}=7.5 \mathrm{~Hz}, \mathrm{H} 8\right), 7.84\left(\mathrm{~d}, 1 \mathrm{H},{ }^{3} J_{\mathrm{H}, \mathrm{F}}=13.5\right.$ $\mathrm{Hz}, \mathrm{H} 5), 8.23$ (t, 1H, J = 6.5 Hz, NH), $8.62(\mathrm{~s}, 1 \mathrm{H}$, $\mathrm{H} 2), 15.2$ (br s, $1 \mathrm{H}, \mathrm{OH}) ;{ }^{13} \mathrm{C}$ NMR $(125 \mathrm{MHz}$, 
DMSO-d $\left.{ }_{6}\right): \delta 8.0\left(2 \mathrm{CH}_{2}\right), 35.1(\mathrm{CH}), 49.6\left(2 \mathrm{C} 3^{\prime}\right)$, 49.8, $49.9\left(2 \mathrm{C}^{\prime}\right), 60.7\left(\mathrm{NCH}_{2} \mathrm{~N}\right), 106.7\left(\mathrm{~d},{ }^{3} J_{\mathrm{C}, \mathrm{F}}=\right.$ 3.5, C8), $107.1(\mathrm{C} 3), 111.5\left(\mathrm{~d},{ }^{2} J_{\mathrm{C}, \mathrm{F}}=23.0, \mathrm{C} 5\right)$, $119.0\left(\mathrm{~d},{ }^{3} J_{\mathrm{C}, \mathrm{F}}=8.0, \mathrm{C} 4 \mathrm{a}\right), 127.6(\mathrm{ArC} 5), 129.3$ (ArC6), 130.0 (ArC3), 130.1 (ArC4) 131.2 (ArC5), $139.6(\mathrm{C} 8 \mathrm{a}), 145.6\left({ }^{2} J_{\mathrm{C}, \mathrm{F}}=10.0, \mathrm{C} 7\right), 153.0\left(\mathrm{~d},{ }^{1} J_{\mathrm{C}, \mathrm{F}}\right.$ $=250.0, \mathrm{C} 6), 166.7(\mathrm{COOH}), 167.8(\mathrm{CONH})$, $176.6\left(\mathrm{~d},{ }^{4} J_{\mathrm{C}, \mathrm{F}}=2.5 \mathrm{~Hz}, \mathrm{C} 4\right)$; Anal. Calc. for: $\mathrm{C}_{25} \mathrm{H}_{24} \mathrm{ClFN}_{4} \mathrm{O}_{4}: \mathrm{C}, 60.18 ; \mathrm{H}, 4.85 ; \mathrm{Cl}, 7.11 ; \mathrm{F}$, $3.81 ; \mathrm{N}, 11.23 ;$ O, 12.83; TOF-MS-ES ${ }^{+}(\mathrm{m} / \mathrm{z})$ : $521.1069[\mathrm{M}+\mathrm{Na}]^{+}, \mathrm{C}_{25} \mathrm{H}_{24} \mathrm{ClFN}_{4} \mathrm{O}_{4}$.

\subsection{General procedure for synthesis of (ben- zoylamino)methyl derivatives of PIPEM (7a-d)}

To separated mixtures of $\mathbf{3}$ (1 equiv.) and 4a-e (1.5 equiv.) in $10 \mathrm{ml}$ DMSO, TEA was added and allow to stir for $3 \mathrm{~h}$ at $35{ }^{\circ} \mathrm{C}$. Afterwards, water was added until a white precipitate was formed. The precipitate was collected by filtration under pressure, washed with water and dried at room temperature to obtain white-yellow crystals. The products were re-crystallized by dissolving in DMSO and precipitation with water. For each product, the reactions were monitored with TLC (mobile phase $\mathrm{CHCl}_{3}: \mathrm{MeOH}, 4: 1$ ). Yields of purified products were from $79.38 \%$ to $98.4 \%$.

\subsubsection{Synthesis of 8-ethyl-2-\{4[(benzoylamino) methyl]piperazin-1-yl\}-5-oxo-5,8-dihydropyrido [2,3-d]pyrimidine-6-carboxylic acid (7a)}

Compound 7a was prepared using the above general procedure in yield $81 \% ; \mathrm{M}_{\mathrm{p}} 193-194{ }^{\circ} \mathrm{C}$; $\mathrm{M}_{\mathrm{w}}$ 436.46; FT- IR-ATR $3274.71 \mathrm{~cm}^{-1} v(\mathrm{~N}-\mathrm{H})$; $2818.99 \mathrm{~cm}^{-1} v(\mathrm{C}-\mathrm{H}) ; 1723.33 \mathrm{~cm}^{-1}$ (Amide I); $1629.6 \mathrm{~cm}^{-1}$ (Amide II). ${ }^{1} \mathrm{H}$ NMR $(600 \mathrm{MHz}$, DMSO-d $\left.{ }_{6}\right): \delta 1.34\left(\mathrm{t}, 3 \mathrm{H}, J=7.5 \mathrm{~Hz}, \mathrm{CH}_{3}\right), 2.64$, $3.86,3.95\left(4 \mathrm{H}, \mathrm{H} 2{ }^{\prime}\right.$ or H3'), $4.25(\mathrm{~d}, 2 \mathrm{H}, J=6.5 \mathrm{~Hz}$, $\left.\mathrm{NCH}_{2}\right), 4.28\left(\mathrm{q}, 2 \mathrm{H}, J=7.5 \mathrm{~Hz}, \mathrm{CH}_{2} \mathrm{CH}_{3}\right), 7.32$ $(\mathrm{dd} 2 \mathrm{H}, J=8.0 \mathrm{~Hz}$, ArH5), 7.39 (dd, 4H, $J=8.0$ $\mathrm{Hz}, \mathrm{ArH} 3), 7.78(\mathrm{~d}, 2 \mathrm{H}, J=8.0 \mathrm{~Hz}, \mathrm{ArH} 2), 8.63(\mathrm{t}$, $1 \mathrm{H}, J=6.5 \mathrm{~Hz}, \mathrm{NH}), 8.71(\mathrm{~s}, \mathrm{H} 2), 9.07(\mathrm{~s}, 1 \mathrm{H}$, H5), 15.20 (br s, $1 \mathrm{H},-\mathrm{OH}) ;{ }^{13} \mathrm{CNMR}(125 \mathrm{MHz}$, DMSO-d $\left.{ }_{6}\right): \delta 14.6\left(\mathrm{CH}_{3}\right), 43.9\left(2 \mathrm{C} 2^{\prime}\right.$ or $\left.2 \mathrm{C}^{\prime}\right), 46.3$ $\left(\mathrm{CH}_{3} \mathrm{CH}_{2}\right), 49.7,49.4\left(2 \mathrm{C} 3^{\prime}\right.$ or $\left.2 \mathrm{C}^{\prime}\right), 60.7\left(\mathrm{NCH}_{2}\right)$, 108.6 (C4a), 109.9 (C7), 127.4 (ArC2, ArC6), 128.3 (ArC5, ArC3), 131.4 (ArC4), 134.1 (ArC1), 149.9 (C2), 155.3 (C8a), 160.3 (C3), 160.7 (C5), 166.1 (COOH), 168.2 (CONH), 177.3 (C5); Anal. Calc. for $\mathrm{C}_{22} \mathrm{H}_{24} \mathrm{~N}_{6} \mathrm{O}_{4}$ : C, 60.54; H, 5.54; N, 19.25; O, 14.66; HRMS (ESI, pos) $(\mathrm{m} / \mathrm{z}): 459.1525$ $[\mathrm{M}+\mathrm{Na}]^{+}, \mathrm{C}_{22} \mathrm{H}_{24} \mathrm{~N}_{6} \mathrm{O}_{4}$.
2.4.2. Synthesis of 8-ethyl-2-\{4-[(4methylbenzoylamino)methyl]piperazin-1-yl\}-5oxo-5,8-dihydropyrido[2,3-d]pyrimidine-6carboxylic acid $\mathbf{( 7 b )}$

Compound $\mathbf{7 b}$ was prepared using the above general procedure in yield $75.8 \%: \mathrm{M}_{\mathrm{p}} 190-192{ }^{\circ} \mathrm{C}$; $\mathrm{M}_{\mathrm{w}}$ 450.49; FT-IR-ATR $3295.12 \mathrm{~cm}^{-1} v(\mathrm{~N}-\mathrm{H})$; $2818.99 \mathrm{~cm}^{-1} v(\mathrm{C}-\mathrm{H}) ; 1740.08 \mathrm{~cm}^{-1}$ (Amide I); $1644.73 \mathrm{~cm}^{-1}$; (Amide II). ${ }^{1} \mathrm{H}$ NMR (600 MHz, DMSO-d 6 ): $\delta 1.34\left(\mathrm{t}, 3 \mathrm{H}, J=7.0 \mathrm{~Hz}, \mathrm{CH}_{2} \mathrm{CH}_{3}\right)$, $2.33\left(\mathrm{~s}, \mathrm{ArCH}_{3}\right), 2.64,3.95(\mathrm{~m}, 8 \mathrm{H}, \mathrm{H} 2$ ', H3'), $4.21\left(\mathrm{~d}, 2 \mathrm{H}, J=6.0 \mathrm{~Hz}, \mathrm{CH}_{2} \mathrm{~N}\right), 4.38(\mathrm{q}, 2 \mathrm{H}, J=7.0$ $\left.\mathrm{Hz}, \mathrm{CH}_{2} \mathrm{CH}_{3}\right), 7.25(\mathrm{~d}, 2 \mathrm{H}, J=8.0 \mathrm{~Hz}, \mathrm{ArH} 3), 7.76$ (d, 2H, $J=8.0 \mathrm{~Hz}, \operatorname{ArH} 2), 8.94(\mathrm{~s}, 1 \mathrm{H}, \mathrm{H} 2), 9.19$ $(\mathrm{s}, 1 \mathrm{H}, \mathrm{H} 5), 14.8$ (br s, $1 \mathrm{H}, \mathrm{OH}) ;{ }^{13} \mathrm{C}$ NMR $(125$ MHz, DMSO-d $\left.\mathrm{d}_{6}\right): \delta 14.3\left(\mathrm{CH}_{2} \mathrm{CH}_{3}\right), 21.0\left(\mathrm{ArCH}_{3}\right)$, $45.8 \quad\left(\mathrm{CH}_{2} \mathrm{CH}_{3}\right), \quad 49.3, \quad 49.6 \quad\left(2 \mathrm{C}^{\prime}, 2 \mathrm{C} 3^{\prime}\right), \quad 60.4$ $\left(\mathrm{CH}_{2} \mathrm{~N}\right), 108.5(\mathrm{C} 4 \mathrm{a}), 109.6(\mathrm{C} 7), 127.4(\mathrm{ArC} 2$, ArC6), 128.8 (ArC3, ArC5), 134.1 (ArC1), 141.3 (ArC4), 150.8 (C2), 155.2 (C8a), 160.3 (C3), 160.6 (C5), $165.4(\mathrm{COOH}), 167.0(1 \mathrm{C}, \mathrm{CONH}), 177.2$ (C5); Anal. Calc. for $\mathrm{C}_{23} \mathrm{H}_{26} \mathrm{~N}_{6} \mathrm{O}_{4}$ : C, 61.32; $\mathrm{H}$, 5.82; N, 18.66; O, 14.21; HRMS (ESI, pos) $(\mathrm{m} / \mathrm{z})$ : $473.1907[\mathrm{M}+\mathrm{Na}]^{+}, \mathrm{C}_{23} \mathrm{H}_{26} \mathrm{~N}_{6} \mathrm{O}_{4}$.

\subsubsection{Synthesis of 8-ethyl-2-\{4-[(3-} methylbenzoylamino)methyl]piperazin-1-yl\}-5oxo-5,8-dihydropyrido[2,3-d]pyrimidine-6carboxylic acid (7c)

Compound 7c was prepared using the above general procedure in yield $88.9 \% ; \mathrm{M}_{\mathrm{p}} 132{ }^{\circ} \mathrm{C} ; \mathrm{M}_{\mathrm{w}}$ 450.49; FT- IR-ATR $3501 \mathrm{~cm}^{-1}$ and $3288.55 \mathrm{~cm}^{-1}$ $v(\mathrm{~N}-\mathrm{H}) ; 2944.77 \mathrm{~cm}^{-1}$ and $2845.04 \mathrm{~cm}^{-1} v(\mathrm{C}-\mathrm{H})$; $1723.64 \mathrm{~cm}^{-1}$ (Amide I); $1644.73 \mathrm{~cm}^{-1}$; (Amide II). ${ }^{1} \mathrm{H}$ NMR (600 MHz, DMSO-d 6 ): $\delta$ (ppm) $1.33(\mathrm{t}$, $\left.3 \mathrm{H}, J=7.5 \mathrm{~Hz}, \mathrm{CH}_{2} \underline{\mathrm{C}}_{3}\right), 2.32\left(\mathrm{~s}, 3 \mathrm{H}, \mathrm{ArCH}_{3}\right)$, 2.62, 3.89, $3.96\left(\mathrm{~m}, 8 \mathrm{H}, \mathrm{H} 2^{\prime}, \mathrm{H} 3{ }^{\prime}\right), 4.22(\mathrm{~d}, 2 \mathrm{H}, J=$ $\left.7.0 \mathrm{~Hz}, \mathrm{NHCH}_{2}\right), 4.35(\mathrm{q}, 2 \mathrm{H}, J=7.0 \mathrm{~Hz}$, $\left.\mathrm{C}_{2} \mathrm{CH}_{3}\right), 7.31-7.32$ (2H, ArH4, ArH5), 7.64 (m, $1 \mathrm{H}, J=8.0 \mathrm{~Hz}, \mathrm{ArH6}$ ), 7.67 (br s, 1H, ArH6), 8.77 (t, $1 \mathrm{H}, J=7.0 \mathrm{~Hz}, \mathrm{NH}), 8.93$ (s,1H, H2), $9.14(\mathrm{~s}, 1 \mathrm{H}$, H5), 14.8 (br s, $1 \mathrm{H}, \mathrm{OH}) ;{ }^{13} \mathrm{C}$ NMR $(125 \mathrm{MHz}$, DMSO-d 6 ): $\delta 14.4\left(\mathrm{CH}_{2} \mathrm{CH}_{3}\right), 21.0\left(\mathrm{ArCH}_{3}\right), 45.9$ $\left(\mathrm{CH}_{2} \mathrm{CH}_{3}\right), 43.7,49.3,49.5$ (4C, $\left.\mathrm{C}^{\prime}, \mathrm{C}^{\prime}\right), 60.4$ $\left(1 \mathrm{C}, \mathrm{NCH}_{2} \mathrm{~N}\right), 108.5(\mathrm{C} 4 \mathrm{a}), 109.5(\mathrm{C} 7), 124.5$ (ArC6), 127.9 (ArC2), 128.2 (ArC5), 131.9 (ArC4), 134.1 (ArC1), 137.6 (ArC3), 150.7 (C2), 155.1 (C8a), 160.2(C5), 160.5 (C3), 165.3 $(\mathrm{COOH}), 167.2(\mathrm{CONH}), 177.1$ (C5), Anal. Calc. for $\mathrm{C}_{23} \mathrm{H}_{26} \mathrm{~N}_{6} \mathrm{O}_{4} \mathrm{C}, 61.32 ; \mathrm{H}, 5.82 ; \mathrm{N}, 18.66 ; \mathrm{O}$, 14.21; HRMS (ESI, pos) $(\mathrm{m} / z): 473.1907[\mathrm{M}+\mathrm{Na}]^{+}$, $\mathrm{C}_{23} \mathrm{H}_{26} \mathrm{~N}_{6} \mathrm{O}_{4}$. 
2.4.4. Synthesis of 8-ethyl-2-\{4-[(2chlorobenzoylamino)methyl]piperazin-1-yl\}-5-oxo5,8-dihydropyrido[2,3-d]pyrimidine-6-carboxylic $\operatorname{acid}(7 d)$

Compound 7d was prepared using the above general procedure in yield $79.38 \% ; \mathrm{M}_{\mathrm{p}} 198-199$ ${ }^{\circ} \mathrm{C} ; \mathrm{M}_{\mathrm{w}}$ 470.91; FT- IR-ATR $3301 \mathrm{~cm}^{-1}$ and $3288.55 \mathrm{~cm}^{-1} v(\mathrm{~N}-\mathrm{H}) ; 2944.77 \mathrm{~cm}^{-1}$ and 2845.04 $\mathrm{cm}^{-1} v(\mathrm{C}-\mathrm{H}) ; 1720.67 \mathrm{~cm}^{-1}$ (Amide I); $1634.4 \mathrm{~cm}^{-1}$ (Amide II). ${ }^{1} \mathrm{H}$ NMR (600 MHz, DMSO-d 6 ): $\delta$ (ppm) 1.35 (t, 3H, $\left.J=7.5 \mathrm{~Hz}, \mathrm{CH}_{3}\right), 2.66,2.68$, 3.92, 3.98 (m, 8H, H2', H3'), 4.20 (d, 2H, $J=7.0$ $\mathrm{Hz}, \mathrm{NHCH}_{2}$ ), 4.39 (q, $2 \mathrm{H}, J=7.0 \mathrm{~Hz}, \mathrm{CH}_{3} \underline{\mathrm{CH}}_{2}$ ), 7.37 (m, ArH), 7.40-7.44 (m, 2H, ArH, ArH), 7.48 $(\mathrm{m}, 1 \mathrm{H}, \mathrm{ArH}), 8.80(\mathrm{t}, 1 \mathrm{H},, J=7.0 \mathrm{~Hz}, \mathrm{NH}), 8.97$ (s,1H, H7), 9.21 (s,1H, H5), 14.83 (br s, 1H, -OH); ${ }^{13} \mathrm{C}$ NMR (125 MHz, DMSO-d $\left.{ }_{6}\right): \delta 14.4\left(\mathrm{CH}_{3}\right)$, $45.9\left(\mathrm{CH}_{3} \mathrm{CH}_{2}\right), 43.86,43.94,49.1,49.3$ (4C, $\mathrm{C} 2$ ', C3'), $60.2\left(\mathrm{CH}_{2} \mathrm{~N}\right), 108.52(\mathrm{C} 4 \mathrm{a}), 109.5(\mathrm{C} 7)$, $127.1,128.8,129.5,129.6,130.7$ (ArC2, ArC3, ArC4, ArC5), 137.0 (ArC1), 150.8 (C2), 155.1 (C8a), 160.2(C5), 160.6 (C3), $165.33(\mathrm{COOH})$, 167.3 (CONH), 177.16 (C5); Anal. Calc. for $\mathrm{C}_{22} \mathrm{H}_{23} \mathrm{ClN}_{6} \mathrm{O}_{4} \mathrm{C}, 56.11 ; \mathrm{H}, 4.92 ; \mathrm{Cl}, 7.53 ; \mathrm{N}$, 17.85; O, 13.59; TOF-MS-ES ${ }^{+}(\mathrm{m} / \mathrm{z}): 471.1554$ $[\mathrm{M}+\mathrm{H}]^{+}, \mathrm{C}_{22} \mathrm{H}_{23} \mathrm{ClN}_{6} \mathrm{O}_{4}$.

\subsection{Determination of physicochemical properties}

\subsubsection{Determination of solubility}

Solubility of the newly synthesized (benzoylamino)methyl derivatives of (fluoro)quinolones was determined in water $\left(S_{\text {wexp }}\right)$ and in phosphate buffered saline (PBS) pH $7.4\left(\mathrm{~S}_{7.4 \exp }\right)$ using a static equilibrium method [20]. An excess of the compounds was exposed to the solvents; accordingly, the mixtures were allowed to be stirred in a thermostatic water bath at $37 \pm 1{ }^{\circ} \mathrm{C}$ (Haake, SWB 20, Waltham, MA, USA) and the samples were assayed once every $4 \mathrm{~h}$ until the results were replicated three consecutive times. After these times, the supernatant solutions, obtained by ultracentrifugation at 12,000 $\mathrm{rpm}$ for 15 minutes, were filtered to ensure that they were free of particulate matter before sampling. The drug concentration was quantified by UV absorption at $\lambda_{\max } 271-275 \mathrm{~nm}$ for NOR and CIPRO derivatives, and 263-271 nm for PIPEM derivatives, respectively (Shimadzu UV-1800, Japan). The whole procedure was light-protected. Sodium thiosulfate was added to the medium when PBS was used to prevent oxidation. All solubility experiments were repeated at least three times, and the mean values were considered the measured results. The $\log \mathrm{S}_{\text {calc }}\left(\log \mathrm{S}_{\text {wcalc }}\right.$ and $\left.\log \mathrm{S}_{7.4 \mathrm{calc}}\right)$ was calculated by online ChemAxon's software for fast and accurate predictions of basic physicochemical properties such as $\log \mathrm{P}, \log \mathrm{D}, \mathrm{pKa}$ and $\log \mathrm{S}$ (www.chemaxon. com/products/calculatorplugins/property-predictors/; www. chemicalize. org/). ChemAxon's aqueous solubility predictor is based on the topology of the molecules.

\subsubsection{Determination of distribution coefficient}

The experimental distribution coefficient between $n$-octanol and PBS (pH 7.4) $\left(\mathrm{D}_{7.4 \exp }\right)$ was determined by shaking flask method, described also by Abuo-Rahma et al. [8]. Stock solutions of (benzoylamino)methyl derivatives of (fluoro)quinolones in PBS were prepared in concentration of app. $0.2 \mathrm{mg} / \mathrm{ml}$ for all tested compounds, respectively. Afterwards, equal volumes of each solution and $n$-octanol were mixed, vortexed for $3 \mathrm{~min}$ and agitated for $12 \mathrm{~h}$ in a shaking water bath at $25 \pm$ $0.1^{\circ} \mathrm{C}$. The test tubes were protected from light by wrapping in aluminum foil. Before a distribution coefficient was determined, the organic and aqueous phase was mutually saturated by shaking for $24 \mathrm{~h}$ at the temperature of the experiment. After equilibration, the octanol phase was removed with a Pasteur pipette and both phases were assayed spectrophotometrically at $\lambda_{\max } 270-280 \mathrm{~nm}$ for NOR and CIPRO derivatives, and 260-270 nm for PIPEM derivatives, respectively, to determine the concentration of the compounds. The experimental distribution coefficient $\mathrm{D}_{7.4}$ was determined from equation:

$$
\mathrm{D}_{7.4}=\mathrm{Ci}-\mathrm{C} w / \mathrm{C} w^{*} V w / V_{0}
$$

where $\mathrm{C} i$ represents the total concentration of solute in both phases after distribution, $\mathrm{C} w$ the solute concentration in the aqueous phase after distribution; $V w$ represents the volume of the aqueous and $V o$ the volume of the organic phase. All distribution coefficient determinations were made in triplicate. The $\log \mathrm{D}_{7.4 \mathrm{calc}}$ and $\log \mathrm{P}$ were calculated by online ChemAxon's software www.chemaxon.com/products/calculator-plugins/property-predictors/; www. chemicalize.org/, where $\log \mathrm{P}$ predictions are composed of the molecules' atomic increments and the applied modifications include the redefinition of selected atom types to accommodate electron delocalization and the addition of contributions of ionic forms. The $\log \mathrm{P}$ value of zwitterions is calculated from the $\log \mathrm{D}$ at the isoelectric point. Also, the effect of hydrogen bonds on $\log P$ is considered if the formation of a six membered ring between suitable donor and acceptor atoms can take place. 
As the $\log \mathrm{D}$ values are $\mathrm{pH}$-dependent, the $\log \mathrm{D}$ calculation relies on the $\mathrm{pKa}$ prediction process.

\subsubsection{Determination of $\mathrm{pKa}$}

The method was firstly evaluated by titration of phosphoric acid during which its experimental $\mathrm{pKa}$ values were evaluated from the secondderivative, being 2.16, 6.9 and 10.94. These values were in agreement with the $\mathrm{pKa}$ values of phosphoric acid specified by Sigma Aldrich (2.15, 7.02 and 12.32) and literature data for phosphoric acid (2.2, 7.2 and 12.3). The $\mathrm{pH}$ meter was calibrated with NBS standard buffers $\mathrm{pH} 4.001$ and $\mathrm{pH}$ 7.001. The (fluoro)quinolone derivatives were dissolved $(0.001 \mathrm{M})$ separately in a mixture of acetonitrile and water (1:4) and the solutions were mixed with a magnetic stirrer during the titration. Titration was carried out in triplicate at ambient temperature of 23 $\pm 1{ }^{\circ} \mathrm{C}$ to ensure reproducibility. $\mathrm{NaOH}$ or $\mathrm{HCl}$ solution was added drop-wise in a volume of $0.05 \mathrm{ml}$. To reach a reasonably stable $\mathrm{pH}$, sufficient time was allowed for reading (app. 10-15 s) before the next acid/base addition. After each experiment, the $\mathrm{pH}$ probe was thoroughly washed with Milli-Q water and calibrated by standard buffers to eliminate asymmetry potentials that would possibly be generated by temporary exposure to a strong acid or base. The titrant solutions of $\mathrm{NaOH}$ and $\mathrm{HCl}(0.01 \mathrm{M})$ were used and standardized by potassium acid phthalate and sodium carbonate. The exact concentrations were determined to be $0.009725 \mathrm{M}$ and $0.00978 \mathrm{M}$ for $\mathrm{NaOH}$ and $\mathrm{HCl}$, respectively. The $\mathrm{pKa}$ calc was calculated by online ChemAxon's software (www.chemaxon.com/products/calculator-plugins/property-predictors/; www.chemicalize. org/), which predicts the $\mathrm{p} K \mathrm{a}$ values of all proton receiving or donating atoms in a molecule. The prediction is made on the basis of the partial charge distribution calculated on the fly.

\subsection{Antimicrobial screening}

All of the synthesized (fluoro)quinolone derivatives were screened for their antimicrobial activities against Gram-positive (Staphylococcus aureus ATCC 29213, Staphylococcus epidermidis ATCC 12228, Staphylococcus aureus-MR, Streptococcus pneumonia ATCC 6305, Enterococcus ATCC 29212) and Gram-negative bacteria (Escherichia coli ATCC 25922, Klebsiella pneumonia ATCC 700603, Pseudomonas aeruginosa ATCC 27853, Bacteroides fragilis ATCC 23745) and Candida albicans ATCC 10231 by the conventional agar diffusion and dilution methods. All bacteria strains were supplied from Microbiologics USA, except Staphylococcus aureus-MR that was clinically isolated and supplied from the Institute of Microbiology and Parasitology, Faculty of Medicine, Ss. Cyril and Methodius University. The suspension of each microorganism was prepared to 0.5 and 2 standards for bacteria (except for Bacteriodes fragilis as anaerobic bacteria for which the suspension was 3 McFarland) and Candida albicans, respectively. The tested compounds as well as references (NOR, CIPRO and PIPEM) were dissolved in DMSO to an initial concentration of $20 \mathrm{mg} / \mathrm{ml}$ for both NOR and CIPRO and $40 \mathrm{mg} / \mathrm{ml}$ for PIPEM.

For the agar diffusion method, all bacterial strains were inoculated on Muller-Hinton agar (Oxoid, UK), while Candida albicans was inoculated on blood agar medium (Oxoid, UK). Inoculation was performed by sterile swabs and the plates were left to dry for 15 minutes. With the aid of a cork-porer, wells of about $6 \mathrm{~mm}$ diameter and 4 $\mathrm{mm}$ deep were formed. Each compound and the references, $80 \mu \mathrm{l}$ each, were put in the wells, with each well containing each antimicrobial diluted in DMSO and DMSO alone as a control. The commercial disks of NOR, CIPRO and PIPEM, with a concentration of 10,10 and $20 \mu \mathrm{g}$, respectively, were used as controls.

For the agar dilution method, Petri dishes contained different concentrations of the tested compounds in blood agar medium. The dilutions of the compounds with blood agar medium were made to obtain the required concentrations in a range between $4.00-0.125 \mu \mathrm{g} / \mathrm{ml}, \quad 16.00-0.03$ $\mu \mathrm{g} / \mathrm{ml}$ and $16.00-0.125 \mu \mathrm{g} / \mathrm{ml}$ for NOR, CIPRO and PIPEM derivatives, respectively. Such prepared plates were inoculated as macrocolonies with the bacteria and Candida albicans, respectively, and incubated at $37{ }^{\circ} \mathrm{C}$ for $24 \mathrm{~h}$. Afterwards, the minimum inhibitory concentration (MIC) was determined, with the lowest concentration of the test compound resulting in no visible growth on the plate.

\subsection{Statistics}

To reveal a correlation between the experimental and calculated values of the physicochemical parameters, a linear regression was performed. Between the antibacterial activities (logMICs) and physicochemical properties of the synthesized compounds, the parabolic relation was fitted, applying the following general regression:

$$
Y=a \log X^{3}+b \log X^{2}+c \log X+d
$$


where $Y=\log \mathrm{MIC}$; $\log X=\log$ of the physicochemical parameter; $a, b, c$ and $d$ are constants. For the statistical operations, statistical program IBM SPSS 19.0 was used.

\section{RESULTS AND DISCUSSION}

\subsection{Synthesis}

In accordance with the previous findings [21], the free secondary amine group of piperazinyl moiety of quinolones offered an easy way for the incorporation of (benzoylamino)methyl functions, resulting in the synthesis of novel compounds in excellent yields. With the aim to incorporate (benzoylamino)methyl functions on the free nitrogen of the 7-pyperazinyl group of the different (fluoro)quinolones, NOR, CIPRO and PIPEM, the synthetic route outlined in Scheme 1 was used. Different derivatives of [(benzoylamino)methyl] triethylammonium chlorides, which were used for (benzoylamino)methylation of the leading (fluoro)quinolones, were prepared according to the previously developed method [22]. The advantages of the (benzoylamino)methylation procedure used in the study included convenient conditions for the synthesis, fast proceeding of the reaction, relatively uncomplicated isolation and high yields of the products (72-98\%). Also, the (benzoylamino) methylation regents were prepared in relatively high yields (70-80\%) and used without purification, with spectroscopic specification [19]. Preparation of the NOR derivatives 5a-e proceeded by stirring a mixture of NOR (1) (1.0 equivalent) and [(benzoylamino)methyl]triethylammonium salts 4a-d (1.5 equivalents) in dimethyl sulfoxide (DMSO) using triethylamine $\left(\mathrm{Et}_{3} \mathrm{~N}\right)$ as a base, resulting in products with high yields, $82.0 \%$ to $96.4 \%$.

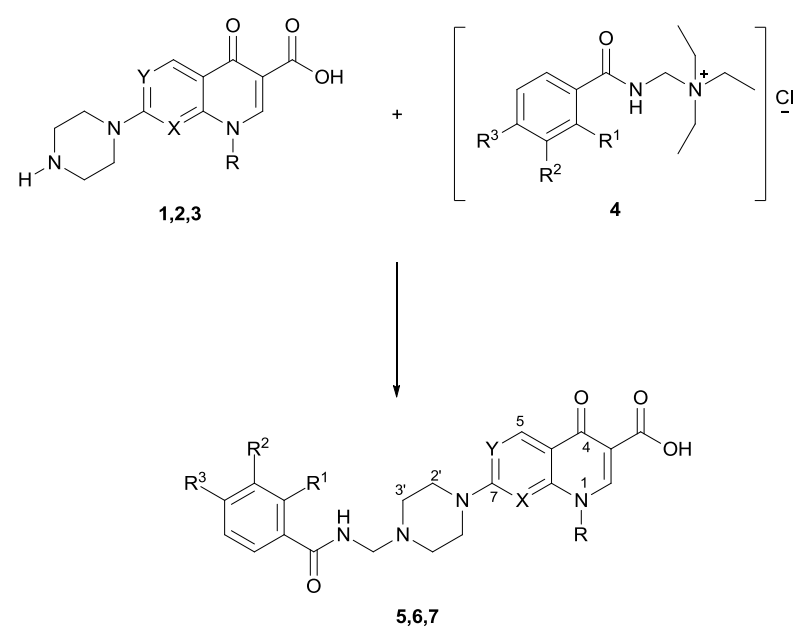

Scheme 1. Synthesis of compounds 5a-e, 6a-d and 7a-d

Table 1

\begin{tabular}{|c|c|c|c|c|c|c|}
\hline Compound & X & $\mathrm{Y}$ & $\mathrm{R}$ & $\mathrm{R}^{1}$ & $\mathrm{R}^{2}$ & $\mathrm{R}^{3}$ \\
\hline 1 (NOR) & $=\mathrm{C}(\mathrm{H})-$ & $=\mathrm{C}(\mathrm{F})-$ & $-\mathrm{C}_{2} \mathrm{H}_{5}$ & - & - & - \\
\hline 2 (CIPRO) & $=\mathrm{C}(\mathrm{H})^{-}$ & $=\mathrm{C}(\mathrm{F})^{-}$ & cyclopropyl & - & - & - \\
\hline 3 (PIPEM) & $=\mathrm{N}-$ & $=\mathrm{N}-$ & $-\mathrm{C}_{2} \mathrm{H}_{5}$ & - & - & - \\
\hline $4 a$ & - & - & - & $\mathrm{H}$ & $\mathrm{H}$ & $\mathrm{H}$ \\
\hline $4 b$ & - & - & - & $\mathrm{H}$ & $\mathrm{H}$ & $-\mathrm{CH}_{3}$ \\
\hline $4 c$ & - & - & - & $\mathrm{H}$ & $-\mathrm{CH}_{3}$ & $\mathrm{H}$ \\
\hline 4d & - & - & - & $\mathrm{H}$ & $\mathrm{Cl}$ & $\mathrm{H}$ \\
\hline $4 e$ & - & - & - & $\mathrm{Cl}$ & $\mathrm{H}$ & $\mathrm{H}$ \\
\hline $5 a$ & $=\mathrm{C}(\mathrm{H})^{-}$ & $=\mathrm{C}(\mathrm{F})^{-}$ & $-\mathrm{C}_{2} \mathrm{H}_{5}$ & $\mathrm{H}$ & $\mathrm{H}$ & $\mathrm{H}$ \\
\hline $5 b$ & $=\mathrm{C}(\mathrm{H})^{-}$ & $=\mathrm{C}(\mathrm{F})^{-}$ & $-\mathrm{C}_{2} \mathrm{H}_{5}$ & $\mathrm{H}$ & $\mathrm{H}$ & $-\mathrm{CH}_{3}$ \\
\hline $5 c$ & $=\mathrm{C}(\mathrm{H})^{-}$ & $=\mathrm{C}(\mathrm{F})^{-}$ & $-\mathrm{C}_{2} \mathrm{H}_{5}$ & $\mathrm{H}$ & $-\mathrm{CH}_{3}$ & $\mathrm{H}$ \\
\hline $5 d$ & $=\mathrm{C}(\mathrm{H})^{-}$ & $=\mathrm{C}(\mathrm{F})^{-}$ & $-\mathrm{C}_{2} \mathrm{H}_{5}$ & $\mathrm{H}$ & $\mathrm{Cl}$ & $\mathrm{H}$ \\
\hline $5 e$ & $=\mathrm{C}(\mathrm{H})^{-}$ & $=\mathrm{C}(\mathrm{F})^{-}$ & $-\mathrm{C}_{2} \mathrm{H}_{5}$ & $\mathrm{Cl}$ & $\mathrm{H}$ & $\mathrm{H}$ \\
\hline $6 a$ & $=\mathrm{C}(\mathrm{H})^{-}$ & $=\mathrm{C}(\mathrm{F})^{-}$ & cyclopropyl & $\mathrm{H}$ & $\mathrm{H}$ & $\mathrm{H}$ \\
\hline 6b & $=\mathrm{C}(\mathrm{H})^{-}$ & $=\mathrm{C}(\mathrm{F})^{-}$ & cyclopropyl & $\mathrm{H}$ & $\mathrm{H}$ & $-\mathrm{CH}_{3}$ \\
\hline $6 c$ & $=\mathrm{C}(\mathrm{H})^{-}$ & $=\mathrm{C}(\mathrm{F})^{-}$ & cyclopropyl & $\mathrm{H}$ & $-\mathrm{CH}_{3}$ & $\mathrm{H}$ \\
\hline 6d & $=\mathrm{C}(\mathrm{H})^{-}$ & $=\mathrm{C}(\mathrm{F})^{-}$ & cyclopropyl & $\mathrm{H}$ & $\mathrm{Cl}$ & $\mathrm{H}$ \\
\hline $7 a$ & $=\mathrm{N}-$ & $=\mathrm{N}-$ & $-\mathrm{C}_{2} \mathrm{H}_{5}$ & $\mathrm{H}$ & $\mathrm{H}$ & $\mathrm{H}$ \\
\hline $7 b$ & $=\mathrm{N}-$ & $=\mathrm{N}-$ & $-\mathrm{C}_{2} \mathrm{H}_{5}$ & $\mathrm{H}$ & $\mathrm{H}$ & $-\mathrm{CH}_{3}$ \\
\hline $7 c$ & $=\mathrm{N}-$ & $=\mathrm{N}-$ & $-\mathrm{C}_{2} \mathrm{H}_{5}$ & $\mathrm{H}$ & $-\mathrm{CH}_{3}$ & $\mathrm{H}$ \\
\hline $7 d$ & $=\mathrm{N}-$ & $=\mathrm{N}-$ & $-\mathrm{C}_{2} \mathrm{H}_{5}$ & $\mathrm{H}$ & $\mathrm{Cl}$ & $\mathrm{H}$ \\
\hline
\end{tabular}


(Benzoylamino)methyl derivatives of CIPRO 6a-d were also obtained in relatively high yields, $71.7 \%$ to $98.2 \%$, by addition of the appropriately substituted [(benzoylamino)methyl] triethylammonium chlorides (4a-d) (1.5 equivalents) to a stirred solution of CIPRO (2) (1.0 equivalent) in water in presence of $\mathrm{Et}_{3} \mathrm{~N}$. Reaction of PIPEM (3) and (benzoylamino)methyl reagents 4a-d (1.5 equivalents) in dimethylformamide (DMF), with subsequent adding of $\mathrm{Et}_{3} \mathrm{~N}$, resulted in the synthesis of the final compounds 7a-d, in yields between 79.4 and $98.4 \%$.

The structure assignments of 5a-e, 6a-d and 7a-d were confirmed by different spectroscopic methods. The ${ }^{1} \mathrm{H}-\mathrm{NMR}$ spectra were identified by their chemical shifts, multiplicities and coupling constants. In general, ${ }^{1} \mathrm{H}$ NMR spectra showed the characteristic chemical shifts for the (fluoro)quinolone nucleus. It showed the absorption characteristic for the piperazine 8 protons, appeared either as a multiplet or two multiplets in the range of 2.71-3.3 ppm. The doublet signal at a range of 6.8-7.2 ppm with $J_{\mathrm{H}-\mathrm{F}}$ of about $7.5 \mathrm{~Hz}$ is characteristic for $\mathrm{H}-8$; the doublet signal at a range of 7.8 $8.1 \mathrm{ppm}$ with $J_{\mathrm{H}-\mathrm{F}}$ of about $9.5-23 \mathrm{~Hz}$ is characteristic for $\mathrm{H}-5$ and the singlet signal characteristic for $\mathrm{H}-2$ at about $8.85-8.95 \mathrm{ppm}$. The signals of four aromatic protons at 7.34-7.9 ppm were also observed as well as doublet $(2 \mathrm{H})$ for the $-\mathrm{N}-\mathrm{CH}_{2}-\mathrm{N}-$ at $4.23 \mathrm{ppm}, 7.0 \mathrm{~Hz}$. In ${ }^{13} \mathrm{C}-\mathrm{NMR}$ spectra of all (benzoylamino)methyl derivatives of the leading (fluoro)quinolones, absorption corresponding to the signal at $60.5 \mathrm{ppm}\left(-\mathrm{N}-\mathrm{CH}_{2}-\mathrm{N}-\right)$ confirmed that the substitution was accomplished.

\subsection{Physicochemical properties}

\subsubsection{Solubility}

The two key properties that contribute to the water solubility of drugs are their ability to ionize and participate in hydrogen bonding interactions. As is already known, (fluoro)quinolones are fairly insoluble in water. Due to the presence of basic amine and carboxylic acid, they possess zwitterionic character. At acidic $\mathrm{pH}$, both amine and acidic groups are protonated providing the molecule positive charge. At high $\mathrm{pH}$ values, amine group is in the free base form, while the carboxyl group exists as a carboxylate anion, providing the overall molecule negative charge. Therefore, the (fluoro)quinolones tend to be more soluble in water at acidic and/or basic $\mathrm{pH}$ [23].

All of the synthesized compounds and the leading (fluoro)quinolones in our study were evaluated for their solubility in water $\left(S_{\text {wexp }}\right)$ and phos- phate buffer solution (PBS) $\mathrm{pH} 7.4$ ( $\left.\mathrm{S}_{7.4 \mathrm{exp}}\right)$. The values of solubility were also calculated by online computational method (http://www.chemicalize.org). The calculated values along with the experimental data are listed in Table 2.

The water solubility of the synthesized derivatives, experimentally determined, was lower than that of the leading compounds, ranging from 0.005 (5b) to $0.030 \mathrm{mg} / \mathrm{ml}$ (5d) for NOR derivatives, $0.024(\mathbf{6 b})$ to $0.055 \mathrm{mg} / \mathrm{ml}$ (6d) for CIPRO derivatives and from $0.005(\mathbf{7 b}, \mathbf{7 c})$ to $0.020 \mathrm{mg} / \mathrm{ml}(\mathbf{7 a})$ for PIPEM derivatives, respectively. As one can notice, NOR and CIPRO substituted with (4methylbenzoylamino)methyl in the piperazinyl moiety (5b and $\mathbf{6 b}$ ) show the lowest water solubility comparing to the corresponding leading compounds, while it slightly increases with the presence of chlorine atom as in (3-chlorobenzoylamino)methyl (5e) and (2-chlorobenzoylamino)methyl (5d and $\mathbf{6 d})$ derivatives of NOR and CIPRO, respectively. Considering the solubility in PBS ( $\mathrm{pH} 7.4$ ), similar values for NOR derivatives were observed, ranging from $0.011 \mathrm{mg} / \mathrm{ml}(\mathbf{5 e})$ to $0.036 \mathrm{mg} / \mathrm{ml}(\mathbf{5 d})$, all being lower than the solubility of NOR $(0.447$ $\mathrm{mg} / \mathrm{ml}$ ). Similar results for the derivatives of CIPRO were observed, where all compounds showed lower solubility than the solubility of the leading compound $(0.114 \mathrm{mg} / \mathrm{ml})$, ranging from $0.009 \mathrm{mg} / \mathrm{ml}$ to $0.058 \mathrm{mg} / \mathrm{ml}$. Among PIPEM derivatives, no significant difference in solubility in PBS (pH 7.4) was observed (ca $0.01 \mathrm{mg} / \mathrm{ml}$ ), being lower than that of PIPEM used in a form of trihydrate $(0.848 \mathrm{mg} / \mathrm{ml})$.

The experimentally determined solubility data for the leading compound NOR are in agreement with the pharmacopeia and literature data that point to very slight water solubility $(0.1-1 \mathrm{mg} / \mathrm{ml})$ and sharp increase in solubility at $\mathrm{pH}$ below 4 and above 10 due to the amphoteric nature [24]. However, there is no agreement between the predicted and experimentally determined data for solubility both in water and PBS (pH 7.4) for this leading compound. Similarly, PIPEM in the form of trihydrate, as used for synthesis, exhibits very slight water solubility $(0.1-1 \mathrm{mg} / \mathrm{ml})$ and solubility in $\mathrm{pH}$ 7.4, dissolving itself in dilute solutions of acids and of alkali hydroxides. These data correlate with the data for the solubility of PIPEM obtained in our study, unlike predicted and experimentally determined values for water solubility and solubility in $\mathrm{pH} 7.4$, respectively, that show weak correlation. Considering CIPRO, it must be noticed that the experimental values for solubility in a form of hydrochloride (as used for the synthesis) are presented in Table 2. As already known, CIPRO is almost insoluble in water $\left(0.08 \mathrm{mg} / \mathrm{ml}\right.$ at $\left.30{ }^{\circ} \mathrm{C}\right)$ [25] and at $\mathrm{pH} 4-5$ it shows the highest solubility 
(>40 $\mathrm{mg} / \mathrm{ml}$ ), but the last solubility corresponds to the hydrochloride form of CIPRO, if the $\mathrm{pH}$ value is adjusted with hydrochloric acid. In neutral $\mathrm{pH}$, CIPRO is almost insoluble, whereas solubility increases with increasing $\mathrm{pH}$ value (app. $30 \mathrm{mg} / \mathrm{ml}$ at $\mathrm{pH} 11)$. Literature data point to $10-30 \mathrm{mg} / \mathrm{ml}$ water solubility for CIPRO $\mathrm{HCl}$ and $0.16-0.17$ $\mathrm{mg} / \mathrm{ml}$ solubility in PBS with $\mathrm{pH}$ ranging from 6.8 to 7.5 [26]. These data are in agreement with the experimental values for solubility of CIPRO obtained in the actual study. However, when comparing the predicted and experimental solubility data for CIPRO $\mathrm{HCl}$ obtained in this study, a weak correlation was observed, as for the other leading compounds.

To determine the relationship between the experimental and calculated values of solubility in $\mathrm{pH}$ 7.4 for all (fluoro)quinolone derivatives synthesized in our study, a simple regression analysis was performed. Weak correlations for the leading compounds and corresponding derivatives were observed $\left(\mathrm{R}^{2}=0.519\right.$ for NOR, $\mathrm{R}^{2}=0.0004$ for CIPRO and $\mathrm{R}^{2}$ $=0.634$ for PIPEM, respectively) (Fig. 1a). However, stronger correlations between $\log S_{\text {wexp }}$ and $\log S_{\text {wcalc }}$ were observed, especially for CIPRO and PIPEM and their derivatives $\left(\mathrm{R}^{2}=0.678\right.$ for NOR, $\mathrm{R}^{2}=0.928$ for CIPRO and $\mathrm{R}^{2}=0.955$ for PIPEM derivatives, respectively) (Fig. 1b).

One can assume that to these results many factors can contribute aside from the zwitterionic character of the (fluoro)quinolones, such as presence of additional acceptor groups that interact with the solvent forming hydrogen bonds, the size of donors and acceptors, which also affects the ability for hydrogen bonding, as well as the melting points of the compounds. As previously reported [23], high melting points, generally above 200 ${ }^{\circ} \mathrm{C}$, indicate that the crystal forms of the compounds are very stable, thus contributing to lower water solubility of (fluoro)quinolones. The lower melting points observed for 5d, 6d and 5e (not higher than $200{ }^{\circ} \mathrm{C}$ ) in comparison with those of other corresponding derivatives and leading compounds and in this respect, their higher water solubility, are in agreement with these observations.

Table 2

Solubility of (benzoylamino)methyl derivatives of NOR, CIPRO and PIPEM

\begin{tabular}{|c|c|c|c|c|c|c|c|}
\hline $\begin{array}{l}\text { Com- } \\
\text { pounds }\end{array}$ & $\begin{array}{c}S_{\text {wcalc }} \\
(\mathrm{mg} / \mathrm{ml})\end{array}$ & $\log S_{\text {wcalc }^{c}}$ & $\log S_{7.4 \mathrm{calc}^{\mathrm{c}}}$ & $\begin{array}{c}S_{\text {wexp }} \\
(\mathrm{mg} / \mathrm{ml})\end{array}$ & $\begin{array}{c}S_{7.4 \exp } \\
(\mathrm{mg} / \mathrm{ml})\end{array}$ & $\log S_{\text {wexp }}{ }^{\mathrm{c}}$ & $\log S_{7.4 \exp }{ }^{\mathrm{c}}$ \\
\hline NOR & $<0.06$ & -2.2 & -2.17 & 0.4975 & 0.4470 & $-5,800$ & $-5,854$ \\
\hline 5 a & $0.01-0.06$ & -4.21 & -2.69 & 0.0098 & 0.0337 & -7.664 & $-7,127$ \\
\hline $5 \mathbf{b}$ & $>0.01$ & -4.69 & -3.16 & 0.0047 & 0.0158 & -7.996 & $-7,470$ \\
\hline $5 \mathrm{c}$ & $>0.01$ & -4.69 & -3.16 & 0.0095 & 0.0150 & -7.691 & $-7,490$ \\
\hline $5 d$ & $>0.01$ & -5.33 & -2.28 & 0.0296 & 0.0362 & -7.216 & $-7,128$ \\
\hline $5 e$ & $>0.01$ & -5.33 & -2.67 & 0.0240 & 0.0116 & -7.307 & $-7,623$ \\
\hline CIPRO $^{\mathrm{a}}$ & $<0.06$ & -2.77 & -2.76 & 11.2405 & 0.1140 & $-4,530$ & $-6,529$ \\
\hline $6 a$ & $>0.01$ & -4.76 & -2.19 & 0.0343 & 0.0581 & -7.131 & $-6,902$ \\
\hline $6 \mathbf{b}$ & $>0.01$ & -5.24 & -2.69 & 0.0245 & 0.0089 & -7.290 & $-7,730$ \\
\hline $6 c$ & $>0.01$ & -5.24 & -2.68 & 0.0289 & 0.0086 & -7.219 & $-7,745$ \\
\hline 6d & $>0.01$ & -5.43 & -2.26 & 0.0552 & 0.0124 & -6.956 & $-7,604$ \\
\hline PIPEM $^{\mathrm{b}}$ & $<0.06$ & -1.75 & -1.73 & 0.4720 & 0.8480 & $-5,879$ & $-5,624$ \\
\hline $7 \mathbf{a}$ & $<0.06$ & -3.78 & -1.88 & 0.0200 & 0.0162 & -7.339 & $-7,430$ \\
\hline $7 b$ & $0.01-0.06$ & -4.26 & -2.37 & 0.0049 & 0.0129 & -7.963 & $-7,543$ \\
\hline $7 c$ & $0.01-0.06$ & -4.26 & -2.37 & 0.0046 & 0.0079 & -7.990 & $-7,756$ \\
\hline 7d & $0.01-0.06$ & -4.45 & -2.48 & 0.0097 & 0.0094 & -7.686 & $-7,699$ \\
\hline
\end{tabular}

an a form of ciprofloxacine hydrochloride;

bin a form of pipemidic acid trihydrate;

cSolubility is expressed in mol/l 

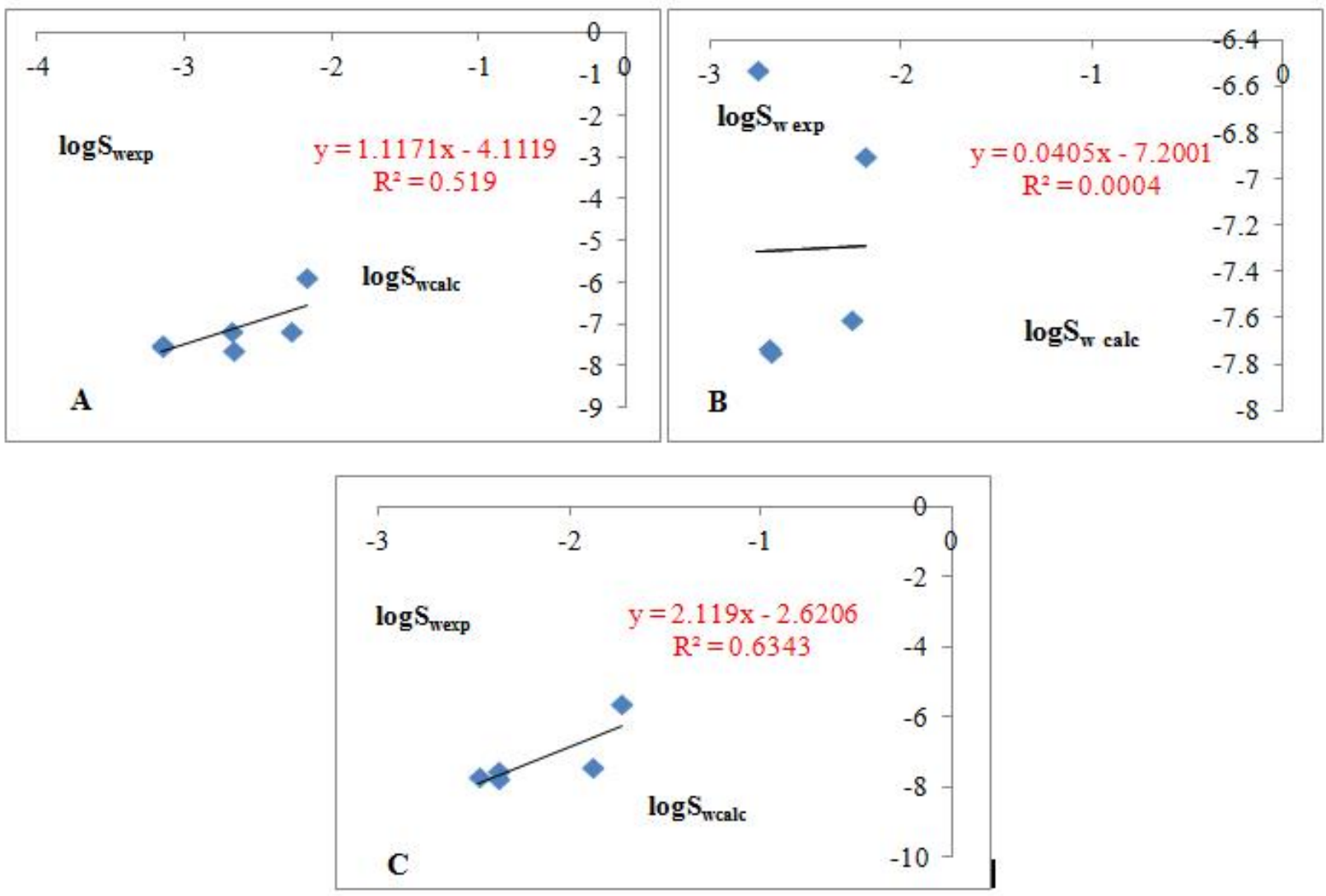

Fig. 1a. Correlation between calculated $\left(\log S_{7.4 c a l c}\right)$ and experimental $\left(\log S_{7.4 \exp }\right)$ values for 5a-e (A), 6a-d (B) and 7a-d (C)
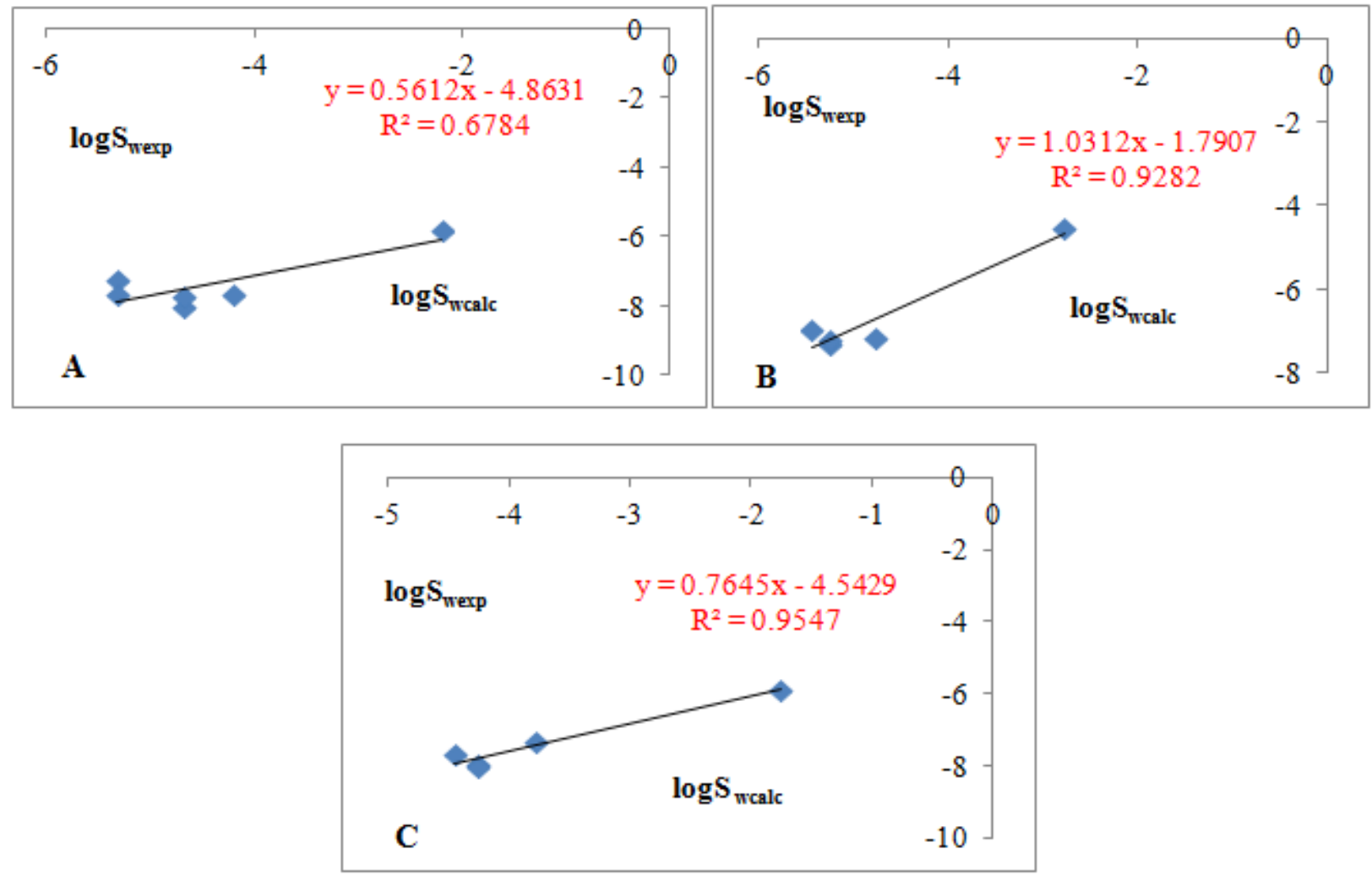

Fig. 1b. Correlation between calculated $\left(\log S_{\text {wcalc }}\right)$ and experimental $\left(\log S_{\text {wexp }}\right)$ values for 5a-e (A), 6a-d (B) and 7a-d (C) 


\subsection{2. $p$ Ka values}

As previously mentioned, (fluoro)quinolones have zwitterionic nature in physiological $\mathrm{pH}$, which is reflected in their solubility, lipophilicity and acidity/basicity. To determine the $\mathrm{p} K_{\mathrm{a}}$ of all synthesized compounds and parent NOR, CIPRO and PIPEM, a potentiometric titration and for analysis, second-derivative method were used. As reported by [27], the second-derivative method, widely used to determine the $\mathrm{pKa}$ 's of most drugs, is the most convenient for the determination of $\mathrm{pKa}$ among the three most applicable (Gran's plot, second-derivative and the least-square non-linear regression), because it is independent of titrate and titrant concentrations. It should be pointed out that the $\mathrm{pKa}$ is assigned a maximum error of $\pm 0.30 \mathrm{pH}$ units when it approaches either end of the titration curve. This is based on the maximum difference between the experimental and actual $\mathrm{pKa}$ of phosphoric acid. The second-derivative method plots $\Delta^{2} \mathrm{pH} / \Delta \mathrm{V}^{2} v s$. $V$; where $V$ is the volume of titrant (acid/base) added and $\Delta V$ is the constant volume increment. On the titration curve, a plot of $\mathrm{pH} v s$. $V$, the inflections occur at both equivalence points and $\mathrm{p} K \mathrm{a}$ value where the value of $\Delta^{2} \mathrm{pH} / \Delta V^{2}$ equals zero. As a result, the $\mathrm{pKa}$ may be readily determined by inspection of the second-derivative plot. The results for the $\mathrm{pKa}$ values of the leading and synthesized compounds are presented in Table 3.

The experimental values obtained for the leading compounds as well as calculated ones did not differ significantly from those reported in the literature: $2.75 \pm 0.40,3.11+0.30,6.10 \pm 0.19,6.34 \pm 8.75$,
$8.60 \pm 0.10,8.76 \pm 0.25,10.56+0.30$ for NOR $[27,28]$, $2.74 \pm 0.40, \quad 3.01 \pm 0.30, \quad 5.9, \quad 6.14 \pm 0.13, \quad 6.30$, $8.70 \pm 0.009,8.76 \pm 0.25,8.89,10.58 \pm 0.3$ for CIPRO [27-29] and $5.25 \pm 0.012, \quad 5.42 \pm 0.05, \quad 5.59 \pm 0.02$, $6.15 \pm 0.06, \quad 6.16, \quad 6.30, \quad 8.18 \pm 0.09, \quad 8.33 \pm 0.01$, $8.90 \pm 0.04$ for PIPEM $[28,30]$, respectively. Considering the $\mathrm{pKa}$ values of the newly synthesized compounds, high correlation between the experimental and calculated $\mathrm{pKa}$ values for each compound was observed $\left(0.873 \geq R^{2} \leq 0.998\right)$.

\subsubsection{Distribution coefficient}

The experimental distribution coefficients between octanol and PBS pH $7.4\left(\mathrm{D}_{7.4 \exp }\right)$ for the newly synthesized compounds (5a-e, 6a-d and 7ad) were also determined. The same was performed for NOR, CIPRO and PIPEM as leading compounds. The calculated values of distribution $\left(\log \mathrm{D}_{7.4 \mathrm{calc}}\right)$ and partition coefficients $(\log \mathrm{P})$, which were determined using computational method developed by ChemAxon (http://www.chemicalize. org//), are listed in Table 3 along with the experimental values $\log \mathrm{D}_{7.4 \exp }$. The experimental distribution coefficients of NOR and CIPRO derivatives were higher than those of the corresponding leading compounds, with the $\log \mathrm{D}_{7.4 \exp }$ of NOR derivatives ranging from -0.81 to 0.58 ( $v s$. $\log \mathrm{D}_{7.4 \exp }-0.89$ for NOR) and of CIPRO derivatives from -0.45 to 0.67 (vs. $\log \mathrm{D}_{7.4 \exp }-1.08$ for CIPRO). Considering derivatives of PIPEM, $\log \mathrm{D}_{7.4 \mathrm{exp}}$ values higher than the one of PIPEM for $7 \mathrm{c}\left(\log \mathrm{D}_{7.4 \exp } 0.34\right)$ and $7 \mathrm{e}$ $\left(\log \mathrm{D}_{7.4 \exp }-0.06\right)$ were observed $\left(v s . \log \mathrm{D}_{7.4 \exp }-0.90\right.$ for PIPEM).

T a b l e 3

$\log D_{7.4 e x p}, \log D_{7.4 c a l}, \log P$ and $p K a$ of (benzoylamino)methyl derivatives of NOR, CIPRO and PIPEM

\begin{tabular}{cccccccc}
\hline \hline Compound & LogD $_{\text {7.4exp }}$ & $\operatorname{logD}_{\text {7.4calc }}$ & LogP & pKaexp & pKacalc & pI $_{\text {exp }}$ & pI calc \\
\hline NOR & -0.89 & -0.92 & -0.92 & $5.5 ; 6.22 ; 8.69$ & $5.77 ; 8.68$ & 5.86 & 7.37 \\
$\mathbf{5 a}$ & 0.30 & 1.18 & 2.67 & $4.9 ; 6.97 ; 8.55$ & $4.28 ; 5.79 ; 14.82$ & 5.93 & 5.18 \\
$\mathbf{5 b}$ & -0.18 & 1.70 & 3.18 & $4.43 ; 6.42 ; 7$ & $4.31 ; 5.79 ; 15.05$ & 5.42 & 5.13 \\
$\mathbf{5 c}$ & -0.36 & 1.60 & 3.18 & $6.75 ; 7.41 ; 8.92$ & $4.30 ; 5.79 ; 14.89$ & 7.08 & 5.20 \\
$\mathbf{5 d}$ & 0.58 & -1.35 & 3.29 & $4.46 ; 6.29 ; 9.2$ & $4.18 ; 5.78 ; 14.39$ & 5.37 & 5.19 \\
$\mathbf{5 e}$ & -0.81 & -1.31 & 3.42 & $4.91 ; 6.35 ; 7$ & $4.25 ; 3.61 ; 13.61$ & 5.63 & 4.87 \\
$\mathbf{C I P R O}$ & -1.08 & -2.4 & -0.81 & $2.58 ; 5.58 ; 9.84$ & $5.76 ; 8.68$ & 4.08 & 7.37 \\
$\mathbf{6 a}$ & 0.15 & -1.82 & 2.77 & $4.85 ; 6.36 ; 7.52 ; 9.155$ & $4.28 ; 5.77 ; 14.82$ & 5.60 & 5.17 \\
$\mathbf{6 b}$ & -0.29 & -1.31 & 3.28 & $3.58 ; 6.35 ; 7.06 ; 8.82$ & $4.31 ; 5.78 ; 15.05$ & 4.96 & 5.19 \\
$\mathbf{6 c}$ & 0.67 & -1.31 & 3.28 & $4.29 ; 6.58 ; 8.67 ;$ & $4.28 ; 5.78 ; 14.89$ & 5.43 & 5.17 \\
$\mathbf{6 d}$ & -0.45 & -1.22 & 3.53 & $5.32 ; 6.4 ; 8.52$ & $3.67 ; 5.76 ; 13.43$ & 5.86 & 4.87 \\
$\mathbf{P I P E M}$ & -0.90 & -2.85 & -2.85 & $4.72 ; 6.3 ; 7.93$ & $1.24 ; 5.31 ; 8.57$ & 5.51 & 7.09 \\
$\mathbf{7 a}$ & -0.98 & -2.3 & -2.30 & $5.99 ; 7.1 ; 9.16$ & $4.26 ; 5.35 ; 14.82$ & 6.54 & 4.95 \\
$\mathbf{7 b}$ & -1.11 & -1.79 & -1.79 & $5.68 ; 6.88 ; 8.1$ & $4.29 ; 5.35 ; 15.05$ & 6.28 & 4.96 \\
$\mathbf{7 c}$ & 0.34 & -1.79 & -1.79 & $6.35 ; 5.23 ; 9.2$ & $4.28 ; 5.35 ; 14.89$ & 5.79 & 4.96 \\
$\mathbf{7 e}$ & -0.06 & -1.7 & -1.70 & $6.6 ; 5.96 ; 5.3$ & $3.65 ; 5.32 ; 13.43$ & 5.63 & 4.63 \\
\hline \hline
\end{tabular}


To reveal a correlation between the experimental and calculated values, a linear regression was performed. Weak correlation $\left(\mathrm{R}^{2}=0.244\right)$ between the calculated $\log \mathrm{P}$ and the experimental values $\log \mathrm{D}_{7.4 \exp }$ for all synthesized compounds was observed (Fig. 2A), with $\mathrm{R}^{2}=0.046$ for NOR, $\mathrm{R}^{2}=0.332$ for CIPRO and $\mathrm{R}^{2}=0.261$ for PIPEM derivatives, respectively. Similarly, when considering correlation between the $\log \mathrm{D}_{7.4 \text { calc }}$ and $\log \mathrm{D}_{7.4 \exp }$ values, low correlation was observed for all synthesized compounds $\left(\mathrm{R}^{2}=0.086\right)$ (Fig. 2B) and for the corresponding derivatives, separately $\left(\mathrm{R}^{2}=0.031\right.$ for NOR, $\mathrm{R}^{2}=0.333$ for CIPRO and $\mathrm{R}^{2}$ $=0.264$ for PIPEM derivatives, respectively.

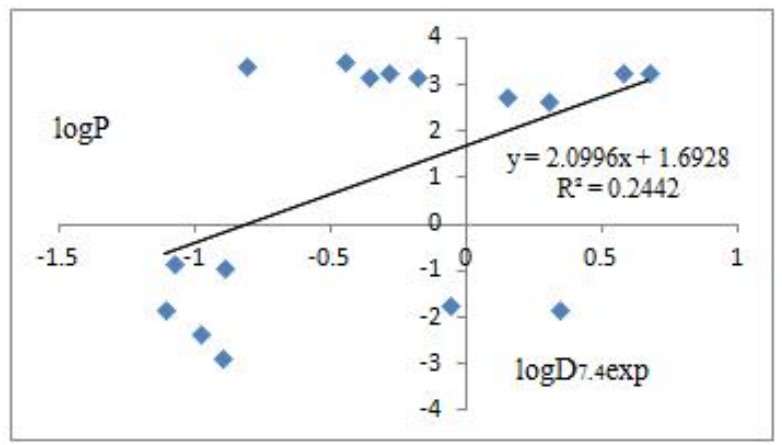

A

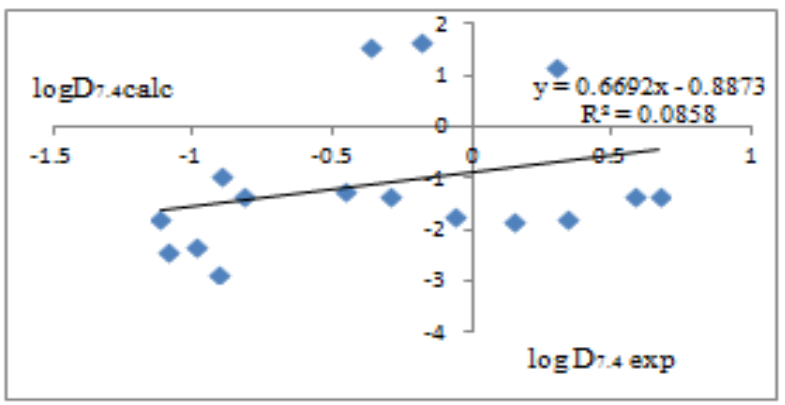

B

Fig. 2. Correlation between: $\log \mathrm{D}_{7.4 \exp }$ and $\log \mathrm{P}(\mathrm{A})$ and $\log \mathrm{D}_{7.4 \exp }$ and $\log \mathrm{D}_{7.4 \mathrm{calc}}$ (B) for all (fluoro)quinolone derivatives

Similar data were reported from other researchers as well [8]. One of the reasons for this weak correlation may be the zwitterionic nature of the (fluoro)quinolones at physiological $\mathrm{pH}$. It is clear that at $\mathrm{pH}$ corresponding to the isoelectric point, zwitterions and neutral molecules are present at their highest concentrations. Therefore, this ratio is a remarkably important feature to describe the lipophilicity of (fluoro)quinolones [31]. Our results revealed that the isoelectric points of the synthesized compounds are around $\mathrm{pH}$ 5-6. According to Kujawski et al. [32, 33], predicted $\log P$ is calculated only for neutral compounds. This may be a reason for the flimsy correlation between the predicted and experimental values. Programs for calculating $\log \mathrm{P}$ are based on breaking molecules into fragments and summing these constant fragment values plus certain correction factors. Considering that, polyprotic equation becomes more complicated and potentially accumulates errors due to the $\log \mathrm{P}$ and $\mathrm{pKa}$ predictions. Consequently, all revealed facts from above may contribute to poor correlation between experimental and calculated values.

\subsection{Antibacterial screening}

The antimicrobial activities of the synthesized quinolone derivatives were screened against Gram-positive (S. aureus ATCC 29213, S. epidermidis ATCC 12228, S. aureus-MR (clinically isolated), S. pneumonia ATCC 6305, Enterococcus ATCC 29212) and Gram-negative bacteria (E. coli ATCC 25922, K. pneumonia ATCC 700603, $P$. aeruginosa ATCC 27853, B. fragilis ATCC 23745) and $C$. albicans ATCC 10231 by the conventional agar diffusion and dilution methods, with NOR, CIPRO and PIPEM as reference compounds. The diameters of the zones of inhibition $(\mathrm{mm})$ along with the minimum inhibitory concentrations (MICs) are presented in Table 4.

All NOR derivatives showed similar antibacterial activities to NOR (the parent compound) in vitro. Specifically, compounds $\mathbf{5 a}$ and $\mathbf{5 b}$ showed higher activity against $S$. aureus compared to $\mathbf{5 c}, \mathbf{5 d}$ and $\mathbf{5 e}$, while activities against other bacteria were similar for all NOR derivatives. CIPRO derivatives exhibited good activity against Grampositive, including methicillin resistant $S$. aureus and Gram-negative bacteria, although this was lower than that of CIPRO. Antibacterial screening of compounds against $S$. aureus, $S$. aureus-MR, $K$. pneumonia, $P$. aeruginosa and Enterococcus revealed that compounds $\mathbf{6 a}$ and $\mathbf{6 b}$ have higher in vitro antibacterial activities compared to $\mathbf{6 c}$ and $\mathbf{6 e}$, with compound $\mathbf{6 b}$ showing the same activity as the leading compound CIPRO in respect to $S$. aureus-MR, S. epidermidis, Enterococcus, S. pneumoniae, E. coli and $K$. pneumoniae. The inhibition zones and MICs of compounds 7a-d indicate that they retained antibacterial activity of the parent compound PIPEM.

Similar to their leading compounds, all synthesized compounds showed no significant activity against $C$. albicans.

Considering literature data [3], the addition of an alkyl group or some type of bulky (5- or 6membered rings) on nitrogen linked to carbon at position 7 in the quinolone moiety resulted in increased activity against aerobic Gram-negative and Gram-positive bacteria, prolonging elimination half-life and increasing bioavailability. It was also observed that increased bulkiness/hydrophobic 
T a ble 4

The diameter of the zone of inhibition ( $\mathrm{mm}$ ) and minimum inhibitory concentrations (MICs $\mathrm{mg} / \mathrm{ml}$ ) of synthesized (fluoro)quinolone derivatives

\begin{tabular}{|c|c|c|c|c|c|c|c|c|c|c|}
\hline $\begin{array}{l}\text { Com- } \\
\text { pounds }\end{array}$ & $\begin{array}{c}\text { Inhibition } \\
\text { zone } \\
(\mathbf{m m})\end{array}$ & $\begin{array}{c}\text { MIC } \\
(\mathrm{mg} / \mathrm{l})\end{array}$ & $\begin{array}{c}\text { Inhibition } \\
\text { zone } \\
(\mathbf{m m})\end{array}$ & $\begin{array}{c}\text { MIC } \\
(\mathrm{mg} / \mathrm{l})\end{array}$ & $\begin{array}{c}\text { Inhibition } \\
\text { zone } \\
(\mathbf{m m})\end{array}$ & $\begin{array}{c}\text { MIC } \\
(\mathrm{mg} / \mathrm{l})\end{array}$ & $\begin{array}{c}\text { Inhibition } \\
\text { zone } \\
(\mathbf{m m})\end{array}$ & $\begin{array}{c}\text { MIC } \\
(\mathrm{mg} / \mathrm{l})\end{array}$ & $\begin{array}{c}\text { Inhibition } \\
\text { zone } \\
(\mathbf{m m})\end{array}$ & $\begin{array}{c}\text { MIC } \\
(\mathrm{mg} / \mathrm{l})\end{array}$ \\
\hline & \multicolumn{2}{|c|}{ S. aureus } & \multicolumn{2}{|c|}{ S. aureus MR } & \multicolumn{2}{|c|}{ S. epidermidis } & \multicolumn{2}{|c|}{ Enterococcus } & \multicolumn{2}{|c|}{ S. pneumoniae } \\
\hline NOR & 25 & 0.25 & 22 & 0.5 & 30 & 0.03 & 13 & 2 & 15 & 1 \\
\hline $\mathbf{5 a}$ & 21 & 0.5 & 22 & 1 & 24 & 0.25 & 10 & 4 & 13 & $>4$ \\
\hline $5 b$ & 22 & 0.5 & 22 & 1 & 22 & 0.50 & 10 & 4 & 14 & 2 \\
\hline $5 c$ & 20 & 1 & 21 & 1 & 22 & 0.50 & 8 & $>4$ & 12 & $>4$ \\
\hline 5d & 19 & 1 & 19 & 1 & 20 & 1 & 6 & $>4$ & 10 & $>4$ \\
\hline $5 e$ & 20 & 1 & 20 & 1 & 21 & 0.50 & 7 & $>4$ & 12 & $>4$ \\
\hline CIPRO & 28 & $\leq 0.03$ & 28 & $\leq 0.03$ & 33 & $\leq 0.03$ & 21 & 1 & 31 & 0.5 \\
\hline $6 a$ & 28 & 0.06 & 28 & 0.125 & 32 & 0.12 & 22 & 1 & 31 & 0.5 \\
\hline $6 b$ & 26 & 0.06 & 28 & $\leq 0.03$ & 33 & $\leq 0.03$ & 21 & 1 & 30 & 0.5 \\
\hline $6 c$ & 23 & 0.25 & 26 & 0.25 & 29 & 0.12 & 16 & 4 & 26 & 1 \\
\hline 6d & 22 & 0.5 & 24 & 0.5 & 27 & 0.5 & 15 & 4 & 26 & 1 \\
\hline PIPEM & 6 & 8 & 6 & $>16$ & 6 & $>16$ & 6 & $>16$ & 6 & $>16$ \\
\hline $7 a$ & 6 & $>16$ & 6 & $>16$ & 6 & $>16$ & 6 & $>16$ & 6 & $>16$ \\
\hline $7 b$ & 11 & $>16$ & 11 & $>16$ & 6 & $>16$ & 6 & $>16$ & 6 & $>16$ \\
\hline $7 \mathrm{c}$ & 11 & 8 & 11 & $>16$ & 6 & $>16$ & 6 & $>16$ & 6 & $>16$ \\
\hline \multirow[t]{2}{*}{ 7d } & 13 & 8 & 13 & $>16$ & 6 & $>16$ & 6 & $>16$ & 6 & $>16$ \\
\hline & \multicolumn{2}{|c|}{ E. coli } & \multicolumn{2}{|c|}{ K. pneumoniae } & \multicolumn{2}{|c|}{ P. aeruginosa } & \multicolumn{2}{|c|}{ B. fragilis } & \multicolumn{2}{|c|}{ C. albicans } \\
\hline NOR & 38 & 0.06 & 23 & 0.5 & 26 & 0.25 & 10 & n.t. & 10 & $>4$ \\
\hline $5 \mathbf{a}$ & 33 & 0.25 & 20 & $>4$ & 15 & 2 & 15 & n.t. & 13 & $>4$ \\
\hline $5 b$ & 35 & 5 & 20 & $>4$ & 18 & 1 & 14 & n.t. & 13 & $>4$ \\
\hline $5 c$ & 33 & 0.25 & 18 & $>4$ & 18 & 1 & 9 & n.t. & 13 & $>4$ \\
\hline $5 d$ & 32 & 0.25 & 18 & $>4$ & 15 & 2 & 9 & n.t. & 9 & $>4$ \\
\hline $5 e$ & 31 & 0.25 & 20 & $>4$ & 15 & 2 & 13 & n.t. & 9 & $>4$ \\
\hline CIPRO & 45 & $\leq 0.03$ & 29 & 0.25 & 35 & 0.25 & 18 & n.t. & 8 & $\leq 16$ \\
\hline $6 a$ & 40 & $\leq 0.03$ & 27 & 0.25 & 31 & 0.5 & 16 & n.t. & 8 & $\leq 16$ \\
\hline 6b & 42 & $\leq 0.03$ & 24 & 0.25 & 29 & 1 & 9 & n.t. & 6 & $\leq 16$ \\
\hline $6 c$ & 39 & $\leq 0.03$ & 23 & 1 & 26 & 2 & 9 & n.t. & 6 & $\leq 16$ \\
\hline 6d & 39 & $\leq 0.03$ & 22 & 2 & 26 & 2 & 7 & n.t. & 7 & $\leq 16$ \\
\hline PIPEM & 6 & 2 & 10 & $>16$ & 6 & $>16$ & 9 & n.t. & 6 & $>16$ \\
\hline $7 \mathbf{a}$ & 6 & 8 & 6 & $>16$ & 6 & $>16$ & 8 & n.t. & 6 & $>16$ \\
\hline $7 b$ & 6 & 4 & 6 & $>16$ & 6 & $>16$ & 8 & n.t. & 6 & $>16$ \\
\hline $7 c$ & 6 & 4 & 6 & $>16$ & 6 & $>16$ & 6 & n.t. & 6 & $>16$ \\
\hline 7d & 6 & 4 & 6 & $>16$ & 6 & $>16$ & 6 & n.t. & 6 & $>16$ \\
\hline
\end{tabular}

n.t.: not tested

substituents at C-7 provided protection from the bacterial efflux transporters, thus reducing the possibility for bacterial resistance in wild-type bacterial strains $[34,35]$.

As confirmed in previous studies [34, 36, 37], moxifloxacin (MOXI) and trovafloxacin (TROVA) are the currently available agents with the greatest bulk at this position, being least affected by exporter proteins. Research data [35] also showed that benzyl substitution at C-7 markedly affected the pharmacological profile of CIPRO with respect to recognition by efflux transporters and cellular accumulation. These findings were not confirmed in our study, having in regard the similar or lower antimicrobial activity against most of the tested strains of the synthesized compounds in comparison with the leading ones. In addition, substitutions and myriad modifi- cations in the quinolone core, specifically at position C-7, may change the primary target. Namely, as Brighty and Gootz pointed out, if CIPRO, TROVA, gemifloxacn (GEMI) and NOR select first a parC mutation, the primary target of MOXI and gatifloxacin (GATI) is gyrA [23].

\subsection{Correlation between physicochemical properties and MIC}

The correlation between $\log S_{\text {wexp }}$ and $\log$ MIC for NOR derivatives was strong in respect to all tested microorganisms, ranging from $\mathrm{R}^{2}=0.844$ to $\mathrm{R}^{2}=0.999$ for $S$. aureus and E. coli, respectively. In the case of CIPRO derivatives, moderate to strong correlation was found between $\log S_{\text {wexp }}$ and $\log$ MIC $\left(0.404 \leq \mathrm{R}^{2} \geq 0.949\right.$ for Enterococcus/S. 
pneumonia and S. epidermidis, respectively) and no correlation in respect to E. coli (Table 5a). Also, no correlation was seen between $\log S_{\text {wexp }}$ and $\log$ MIC for PIPEM derivatives, except a moderate one in the case of $S$. aureus $\left(\mathrm{R}^{2}=0.489\right)$ and a strong one in the case of $E$. coli $\left(\mathrm{R}^{2}=0.999\right)$. The correlation between the $\log \mathrm{S}_{\text {wcalc }}$ and $\log$ MIC was strong in respect to all tested bacteria when considering NOR derivatives $\left(0.85 \leq \mathrm{R}^{2} \geq 0.995\right)$, except for $E$. coli. For CIPRO derivatives, strong correlation in respect to $P$. aeruginosa only and moderate for the others (except for $E$. coli) was observed, while for PIPEM derivatives, specifically, strong correlation in respect to $E$. coli only were observed, being moderate in respect to $S$. aureus and showing an absence of correlation when considering other bacteria (Table 5a).

In general, the correlation between $\log \mathrm{S}_{7.4 \exp }$ and $\log$ MIC was similar for NOR $\left(0.609 \leq \mathrm{R}^{2} \geq\right.$ $0.999)$, CIPRO $\left(0 \leq \mathrm{R}^{2} \geq 0.916\right)$ and PIPEM derivatives $\left(0 \leq R^{2} \geq 0.965\right)$ with the correlation between $\log S_{\text {wexp }}, \log S_{\text {wcalc }}, \log S_{7.4 \text { calc }}$ and $\log$ MIC, respectively, except for the higher correlation for PIPEM derivatives in the case of $S$. aureus $\left(\mathrm{R}^{2}=\right.$ 0.891) (Table 5a).

It is expected that in non-polar media, such as lipids in the cell membrane, the solubility of neutral molecules is higher, so they can easily pass through cell membranes and show good bioavailability. In contrast, zwitterions, such as (fluoro)quinolones, have a greater affinity for polar environments and penetrate easily through pores in bacterial cell walls, after which they readily bind to bacterial gyrase $[8,31]$. This can explain relatively high correlation between $\log S_{\text {wexp }}$ and $\log S_{7.4 \exp }$ and $\log$ MICs of the synthesized compounds for most of the tested bacteria.

For NOR derivatives, strong correlation between $\log \mathrm{MIC}$ and $\log \mathrm{P}$ and $\log \mathrm{D}_{7.4 \mathrm{calc}}$, respectively, was observed for all tested bacteria (Table 5b). However, when considering correlation between experimental $\log \mathrm{D}_{7.4 \mathrm{exp}}$ and $\log \mathrm{MIC}$ for the same derivatives, high correlation in respect to $E$. coli only was obtained $\left(\mathrm{R}^{2}=0.997\right)$. For CIPRO derivatives, strong correlation between $\log \mathrm{MIC}$ and $\log \mathrm{P}$ and $\log \mathrm{D}_{7.4 \mathrm{calc}}$, respectively, in respect to $P$. aeruginosa only $\left(\mathrm{R}^{2}=0.926\right)$ was detected. This was in agreement with the correlation of the experimental $\log \mathrm{D}_{7.4 \exp }$ and $\log \mathrm{MIC}$ for this strain $\left(\mathrm{R}^{2}=0.977\right)$. For PIPEM derivatives, strong correlation only in respect to $E$. coli was observed $\left(\mathrm{R}^{2}=0.946\right)$ when correlating $\log \mathrm{MIC}$ and $\log \mathrm{P}$ and $\log \mathrm{D}_{7.4 \mathrm{calc}}$, respectively. However, no correlation was observed between $\log \mathrm{D}_{7.4 \exp }$ and $\log \mathrm{MIC}$ for this strain $(\mathrm{Ta}-$ ble $5 b)$.
These inconsequential correlations suggest that the lipophilicity of the (fluoro)quinolones is not the only factor that affects their activity, indicating that passive diffusion is not the only way to cross the cell membrane and accumulate in bacterial cells. A similar effect was observed in previous studies, in which a weak correlation was reported between the hydrophobicity and MIC of mixofloxacin for two Gram-positive bacteria (Str. pneumonia and S. aureus-MR) [38] as well as non-proportional correlation between lipophilicity and inhibition of target enzyme (DNA gyrase) and MIC of several (fluoro)quinolones [39]. The opposite effect was observed in a study of Piddock and Johnson [40], who found that with a decrease in hydrophobicity, there was a decrease in the concentration accumulated. However, it must be noticed that in their study, the accumulation of ten fluoroquinolones, including CIPRO and NOR, for only S. pneumonia, two wildtype fluoroquinolone-susceptible capsulated and one non-encapsulated strains, was evaluated. As an explanation for this inconsequential correlation, several factors could be considered, such as steric effects and electronic factors, solubility effect, compound permeability/mechanism of its transport, affinity of the compound for its target enzyme, binding and packaging of the molecules on the active site of the enzyme, molecular mass, etc. It is well-known, for example, that electronic factor and steric effect have a significant impact on the protonation of $\mathrm{N}-4$ piperazinyl group [41].

The $\log \mathrm{D}_{7.4}$ of almost all (fluoro)quinolones are nearly less or close to zero and are not too dissimilar from each other (except TROVA). Interestingly, the true partition coefficients tend to be lower in the second generation (except ofloxacin, pefloxacin and amifloxacin), and appear to be higher in members of the third and fourth generations. A similar trend is revealed in the permeability and thus systemic bioavailability after oral administration, expressed in area under curve plasma concentration vs. time (AUC) [38]. Although it is a fully validated parameter, it has been shown that the AUC/MIC ratio often correlates to antibacterial effects in a preclinical model of infection [42]. How modifications in the structure of the (fluoro)quinolones synthesized in this study will affect bioavailability (AUC) and in this respect MIC in vivo remains to be determined.

Parabolic curve among $\mathrm{M}_{\mathrm{w}}$ and $\log \mathrm{MIC}$ for NOR derivatives (5a-e) resulted in a strong correlation for $S$. aureus $M R\left(\mathrm{R}^{2}=0.999\right)$, Enterococcus $\left(\mathrm{R}^{2}=0.999\right), K$. pneumonia $\left(\mathrm{R}^{2}=0.999\right)$ and $S$. epidermidis $\left(\mathrm{R}^{2}=0.968\right)$ and moderate in respect to other strains $\left(0.577 \leq \mathrm{R}^{2} \geq 0.8571\right)$ (Table $\left.5 \mathrm{~b}\right)$. A 
weaker correlation between these parameters was obtained in the case of CIPRO derivatives for most of the test strains $\left(0.586 \geq R^{2} \leq 0.817\right)$, with higher correlation for $P$. aeruginosa $\left(\mathrm{R}^{2}=0.926\right)$. The same was observed for PIPEM derivatives, as outlined in Table $5 \mathrm{~b}$.

$\mathrm{T}$ able $5 \mathrm{a}$

Correlation $\left(R^{2}\right)$ between antimicrobial activity and solubility of the (fluoro)quinolone derivatives

\begin{tabular}{|c|c|c|c|c|c|c|c|c|c|c|c|c|}
\hline \multirow[b]{2}{*}{ Strain } & \multicolumn{3}{|c|}{$\log S_{\text {wexp }}$} & \multicolumn{3}{|c|}{$\log S_{7.4 \exp }$} & \multicolumn{3}{|c|}{$\log S_{\text {wcalc }}$} & \multicolumn{3}{|c|}{$\log \mathrm{S}_{7.4 \mathrm{calc}}$} \\
\hline & $\begin{array}{l}\text { NOR } \\
\text { deriv. }\end{array}$ & $\begin{array}{c}\text { CIPRO } \\
\text { deriv. }\end{array}$ & $\begin{array}{c}\text { PIPEM } \\
\text { deriv. }\end{array}$ & $\begin{array}{l}\text { NOR } \\
\text { deriv. }\end{array}$ & $\begin{array}{c}\text { CIPRO } \\
\text { deriv. }\end{array}$ & $\begin{array}{c}\text { PIPEM } \\
\text { deriv. }\end{array}$ & $\begin{array}{l}\text { NOR } \\
\text { deriv. }\end{array}$ & $\begin{array}{c}\text { CIPRO } \\
\text { deriv. }\end{array}$ & $\begin{array}{c}\text { PIPEM } \\
\text { deriv. }\end{array}$ & $\begin{array}{l}\text { NOR } \\
\text { deriv. }\end{array}$ & $\begin{array}{l}\text { CIPRO } \\
\text { deriv. }\end{array}$ & $\begin{array}{l}\text { PIPEM } \\
\text { deriv. }\end{array}$ \\
\hline S. aureus & 0.844 & 0.710 & 0.489 & 0.919 & 0.762 & 0.891 & 0.85 & 0.811 & 0.583 & 0.850 & 0.858 & 0.583 \\
\hline S. aureus-MR & 0.997 & 0.818 & 0 & 0.999 & 0.574 & 0 & 0.997 & 0.646 & 0 & 0.997 & 0.694 & 0 \\
\hline S. epidermidis & 0.971 & 0.949 & 0 & 0.995 & 0.746 & 0 & 0.960 & 0.817 & 0 & 0.990 & 0.845 & 0 \\
\hline Enterococcus & 0.997 & 0.404 & 0 & 0.999 & 0.531 & 0 & 0.997 & 0.583 & 0 & 0.997 & 0.642 & 0 \\
\hline S. pneumoniae & 0.997 & 0.404 & 0 & 0.868 & 0.531 & 0 & 0.857 & 0.583 & 0 & 0.857 & 0.642 & 0 \\
\hline E. coli & 0.999 & 0 & 0.999 & 0.609 & 0 & 0.965 & 0.576 & 0 & 0.936 & 0.577 & 0 & 0.565 \\
\hline K. pneumoniae & 0.997 & 0.616 & 0 & 0.995 & 0.684 & 0 & 0.997 & 0.75 & 0 & 0.997 & 0.791 & 0 \\
\hline P. aeruginosa & 0.931 & 0.721 & 0 & 0.995 & 0.916 & 0 & 0.995 & 0.926 & 0 & 0.997 & 0.962 & 0 \\
\hline
\end{tabular}

$\mathrm{Tab} l \mathrm{e} 5 \mathrm{~b}$

Correlation $\left(R^{2}\right)$ between antimicrobial activity and lipophilicity and molecular weight of the (fluoro)quinolone derivatives

\begin{tabular}{|c|c|c|c|c|c|c|c|c|c|c|c|c|}
\hline \multirow[b]{2}{*}{ Strain } & \multicolumn{3}{|c|}{$\log \mathrm{D}_{7.4 \exp }$} & \multicolumn{3}{|c|}{$\log \mathrm{D}_{7.4 \mathrm{calc}}$} & \multicolumn{3}{|c|}{$\log \mathrm{P}$} & \multicolumn{3}{|c|}{$\log \mathrm{M}_{\mathrm{w}}$} \\
\hline & $\begin{array}{l}\text { NOR } \\
\text { deriv. }\end{array}$ & $\begin{array}{c}\text { CIPRO } \\
\text { deriv. }\end{array}$ & $\begin{array}{c}\text { PIPEM } \\
\text { deriv. }\end{array}$ & $\begin{array}{l}\text { NOR } \\
\text { deriv. }\end{array}$ & $\begin{array}{c}\text { CIPRO } \\
\text { deriv. }\end{array}$ & $\begin{array}{l}\text { PIPEM } \\
\text { deriv. }\end{array}$ & $\begin{array}{l}\text { NOR } \\
\text { deriv. }\end{array}$ & $\begin{array}{c}\text { CIPRO } \\
\text { deriv. }\end{array}$ & $\begin{array}{l}\text { PIPEM } \\
\text { deriv. }\end{array}$ & $\begin{array}{l}\text { NOR } \\
\text { deriv. }\end{array}$ & $\begin{array}{r}\text { CIPRO } \\
\text { deriv. }\end{array}$ & $\begin{array}{c}\text { PIPEM } \\
\text { deriv. }\end{array}$ \\
\hline S. aureus & 0.273 & 0.714 & 0.755 & 0.998 & 0.8108 & 0.583 & 0.850 & 0.811 & 0.583 & 0.850 & 0.811 & 0.583 \\
\hline S. aureus-MR & 0.442 & 0.406 & 0 & 0.987 & 0.6463 & 0 & 0.999 & 0.646 & 0 & 0.999 & 0.646 & 0 \\
\hline S. epidermidis & 0.545 & 0.301 & 0 & 0.991 & 0.817 & 0 & 0.957 & 0.817 & 0 & 0.968 & 0.817 & 0 \\
\hline Enterococcus & 0.442 & 0.740 & 0 & 0.987 & 0.5833 & 0 & 0.999 & 0.583 & 0 & 0.999 & 0.583 & 0 \\
\hline S. pneumoniae & 0.243 & 0.740 & 0 & 0.999 & 0.5833 & 0 & 0.857 & 0.583 & 0 & 0.857 & 0.583 & 0 \\
\hline E. coli & 0.997 & 0 & 0.087 & 0.951 & 0 & 0.946 & 0.577 & 0 & 0.946 & 0.577 & 0 & 0.802 \\
\hline K. pneumoniae & 0.442 & 0.631 & 0 & 0.987 & 0.75 & 0 & 0.999 & 0.750 & 0 & 0.999 & 0.750 & 0 \\
\hline P. aeruginosa & 0.395 & 0.977 & 0 & 0.995 & 0.9265 & 0 & 0.951 & 0.926 & 0 & 0.842 & 0.926 & 0 \\
\hline
\end{tabular}

The correlation of molecular size and MIC was the issue that drew the attention of several other researchers. In a study of Piddock and Johnson [40], with an increase in the molecular weight of the free form of each fluoroquinolone, there was a decrease in the concentration accumulated in wild-type or efflux mutant $S$. pneumonia. In addition, a linear relationship between the steady-state concentration and the molecular size of the fluoroquinolones was observed. Out of ten fluoroquinolones, the exception was grepafloxacin (GREPA), with a high molecular weight, similar to that of TROVA and MOXI, but a high concentration accumulated. All of these observations can explain the relatively strong to moderate correlation between the molecular weight and potency of the synthesized (fluoro)quinolone derivatives observed in this study.

\section{CONCLUSION}

Novel (benzoylamino)methyl derivatives of (fluoro)quinolones were synthesized in one step and high yields, starting from the leading compounds NOR, CIPRO and PIPEM, respectively. Addition of (benzoylamino)methyl functions in the piperazinyl ring of the leading compounds by substitution of hydrogen atom at position 4 resulted in the formation of zwitterionic compounds in physiological $\mathrm{pH}$, with lower water solubility and in $\mathrm{pH}$ 7.4 and, consequently, higher lipophilicity than that of the leading compounds, respectively. In- 
creased bulkiness at position $\mathrm{C}-7$ in the quinolone moiety and higher lipophilicity of the synthesized compounds have been shown not to increase antimicrobial activity of the leading compounds, pointing out that passive diffusion is not the only mechanism for penetration into bacterial cells. How substitutions in the (fluoro)quinolone moiety affect the primary target(s), substrate behavior in respect to bacterial efflux and/or influx transporters and overall bioavailability remains to be determined.

Acknowledgements. This work was supported by the Macedonian Academy of Sciences and Arts (grant No 07520/15) and Bulgarian Academy of Sciences (Project BAS MANU/2014 - 2016).

\section{REFERENCES}

[1] L. Pintilie Quinolones: synthesis and antibacterial activity. In: Antimicrobial Agents, Varaprasad B. (Eds), InTech, 2012, pp. 255-272.

[2] A. Foroumadi, S. Emami, M. Mehni, M. H. Moshafi, A. Shafiee, Synthesis and antibacterial activity of N-[2-(5bromothiophen-2-yl)-2-oxoethyl] and N-[2-(5-bromothiophen-2-yl)-2-oximinoethyl] derivatives of piperazinyl quinolones, Bioorg. Med. Chem. Lett, 20, 4536-4539 (2005). DOI: 10.1016/ j.bmcl.2005.07.005.

[3] V. T. Andriole, The Quinolones: Past, Present and Future, Clin. Infect. Dis, 41, 113-119 (2005). DOI: $10.1086 / 428051$.

[4] R. Davis, A. Markham, A. J. Balfour, Ciprofloxacin. An updated review of its pharmacology, therapeutic efficacy and tolerability, Drugs, 51, 1019-1074 (1996).

[5] M. J. Nieto, F. L. Alovero, R. H. Manzo, M. R. Razzieri, Benzenesulfonamide analogs of fluoroquinolones. Antibacterial activity and QSAR studies, Eur. J. Med. Chem, 40, 361-369 (2005).

DOI:10.1016/j.ejmech.2004.11.008.

[6] Y. L. Zhao, Y. L. Chen, J. Y. Sheu, L. I. Chen, T. C. Wang, C. C. Tzeng, Synthesis and antimycobacterial evaluation of certain fluoroquinolone derivatives, Bioorg. Med. Chem, 13, 3921-3926 (2005). DOI: $10.1016 / \mathrm{j} . \mathrm{bmc} .2005 .04 .005$.

[7] G. Zhao, M. J. Miller, S. Franzblau, B. Wan, U. Mollmann, Syntheses and studies of quinolonecephalosporins as potential anti-tuberculosis agents, Bioorg. Med. Chem. Lett, 16, 5534-5537 (2006). DOI: $10.1016 /$ j.bmcl.2006.08.045.

[8] G. E-D. A. A. Abuo-Rahma, H. A. Sarhan, F. G. Gad, Design, synthesis, antibacterial activity and physicochemical parameters of novel N-4-piperazinyl derivatives of norfloxacin, Bio. Med. Chem. 17, 3879-3886 (2009). DOI: 10.1016/j.bmc.2009.04.027.

[9] S. Emami, E. Ghafouri, M. Ali, N. Samadi, H. Irannejad, A. Foroumadi, Mannich bases of 7-piperazinylquinolones and kojic acid derivatives: synthesis, in vitro antibacterial activity and in silico study, Eur. J. Med. Chem, 2013, 68, 185-191 (2013).

DOI:10.1016/j.ejmech.2013.07.032.
[10] D. Sriram, T. Bal Ratan, P. Yogeeswari, D. R. Redha, V. J. Nagraja, Evaluation of antimycobacterial and DNA gyrase inhibition of fluoroquinolone derivatives, J. Gen. Appl. Microbiol, 52, 195-200 (2006).

DOI: 10.2323/jgam.52.195.

[11] S. N. Pandeya, D. Sriram, P. Yogeeswari, S. Ananthan, Antituberculous activity of norfloxacin Mannich bases with isatin derivatives, Chemother, 47, 266-269 (2001). DOI: $10.1159 / 000048533$.

[12] M. Kaul, L. Mark, Y. Zhang, A. K. Parhi, E. J. Lavoie, D. S. Pilch, An FtsZ-targeting prodrug with oral antistaphylococcal efficacy in vivo, Antimicrob. Agents. Chemother, 57, 5860-5869 (2013). DOI: 10.1128/AAC.01016-13.

[13] A. Buur, N. Mork, Prodrugs: Design and development. In: Textbook of Drug Design and Discovery, P. Krogsgaard-Larsen, K. Stromgaard, U. Madsen (Eds), CRC Press Taylor and Francis, 2010, pp. 135-151.

[14] S. Bala, N. Sharma, A. Kajal, S. Kamboj, Design, synthesis, characterization and computational studies on benzamide substituted Mannich bases as novel, potential antibacterial agents, Sci. World J., 2014, Article ID 732141, 1-9 (2014). DOI:10.1155/2014/732141.

[15] A. Doshi, S. G. Deshpande, In vivo pharmacokinetic studies of prodrugs of ibuprofen. Indian. J. Pharm. Sci, 69, 824-827 (2007). DOI: 10.4103/0250-474X.39444

[16] D. Sriram, P. Yogeeswari, M. R. Kishore, Synthesis and anti-HIV activity of nevirapine prodrugs, Pharmazie 61, 895-897 (2006).

[17] V. R. Guarino, V. J. Stella, Prodrugs of amides, imides and other NH-acidic compounds. In: Prodrugs, Challenges and Rewards, H. Maag, J. Tilley, V. Stella, R. Borchardt, M. Hageman, R. Oliyai (Eds), Springer, 2007, pp. 833-887.

[18] P. M. A. Cabrera, D. H. Gonzalez, T. C. Fernandez, J. M. Pla-Delfina, M. S. Bermejo, A novel approach to determining physicochemical and absorption properties of 6-fluoroquinolone, Eur. J. Pharm. Biopharm, 53, 317-342 (2002). DOI: 10.1016/S0939-6411(02)00013-9.

[19] P. Breznica-Selmani, K. Mladenovska, Z. Kavrakovski, B. Mikhova, G. Draeger, E. Popovski, [(3-Chlorobenzamido)methyl]triethylammonium chloride, Molbank 2, M851(2015). DOI:10.3390/M851.

[20] C-L. Zhang, Y. Wang, Aqueous solubilities for ofloxacin, norfloxacin, lomefloxacin, ciprofloxacin, pefloxacin, and pipemidic acid from (293.15 to 323.15$) \mathrm{K}$, J. Chem. Eng, 53, 1295-1297 (2008). DOI: 10.1021/je7007044.

[21] E. Popovski, L. Klisarova, D. Vukić-Topić, Benzamidomethylation with (benzamidomethyl)triethylammonium chloride. 2. A simple method for benzamidomethylation of thiols, amines and carboxylic acids, Molecules, 5, 927-936 (2000). DOI: 10.3390/50700927.

[22] E. Popovski, L. Klisarova, D. Vukić-Topić, Simple method for benzamidomethylation of phenols in water solution. Synth. Commun, 29, 3451-3458 (1999). DOI: $10.1080 / 00397919908085975$.

[23] K. E. Brighty, T. D. Gootz, Chemistry and Mechanism of Action of the Quinolone Antibacterials. In: The Quinolones, V. T. Andriole (Eds), Academic Press, 2000, pp. 33-82. 
[24] K. Dua, M. V. Ramana, U. V. S. Sara, M. Himaja, A. Agrawal, V. Garg, K. Pabreja, Investigation of enhancement of solubility of norfloxacin betacyclodextrin in presence of acidic solubilizing additives, Curr. Drug Delivery, 4, 21-25 (2007). DOI: $10.2174 / 156720107779314776$.

[25] A. I. Caço, F. Varanda, M. J. Pratas de Melo, A. M. A. Dias, R. Dohrn, I. M. Marrucho, Solubility of antibiotics in different solvents. Part II. Non-hydrochloride forms of tetracycline and ciprofloxacin, Ind. Eng. Chem. Res, 47, 8083-8089 (2008). DOI: $10.1021 / \mathrm{ie} 8003495$.

[26] M. E. Olivera, R. H. Manzo, H. E. Junginger, K. K. Midha, V. P. Shah, S. Stavchansky, J. B. Dressman, D. M. Barends, Biowaiver monographs for immediate release solid oral dosage forms: Ciprofloxacin hydrochloride, J. Pharm. Sci, 100, 22-33 (2011). DOI: $10.1002 / j p s .22259$.

[27] Z. Qiang, C. Adams, Potentiometric determination of acid dissociation constants (pKa) for human and veterinary antibiotics, Water. Res, 38, 2874-2890 (2004). DOI: 10.1016/j.watres.2004.03.017.

[28] S. Babic, A. J. Horvat, D. Mutavdz-Pavlovic, Determination of $\mathrm{pKa}$ values of active pharmaceutical ingredients, Trends Analyt. Chem, 2007, 26, 1043-1061 (2007). DOI: $10.1016 / j$.trac.2007.09.004.

[29] C. A. Kan, M. Petz, Residues of veterinary drugs in eggs and their distribution between yolk and white, J. Agric. Food Chem, 48, 6397-6403 (2000). DOI: $10.1021 /$ jf000145p.

[30] H. R. Park, T. H. Kim, K. M. Bark, Physicochemical properties of quinolone antibiotics in various environments Eur. J. Med. Chem, 37, 443-460 (2002). DOI: 10.1016/S0223-5234(02)01361-2.

[31] D. A. Bakhotmah, R. M. Abdul-Rahman, M. S. Makki, M. A. El-Zahabi, and M. Suliman, Synthesis, Physiochemical Properties, Photochemical Probe, and Antimicrobial Effects of Novel Norfloxacin Analogues. ISRN Org. Chem, Article ID 184754, 1-11 (2011). DOI: $10.5402 / 2011 / 184754$.

[32] J. Kujawski, M. Bernard, A. Janusz, W. Kuzma, Prediction of $\log$ P: ALOGPS application in medicinal chemistry education, J. Chem. Educ, 89, 64-67 (2012). DOI:10.1021/ed100444h.

[33] J. Kujawski, H. Popielarska, A. Myka, B. Drbniska, M. Bernard, The $\log \mathrm{P}$ parameter as a molecular descriptor in the computer-aided drug design-an overview. Meth. Sci. Technol, 18, 81-88 (2012). DOI: $10.12921 / \mathrm{cmst} .2012 .18 .02 .81-88$.
[34] L. R. Peterson, Quinolone molecular structure-activity relationships: what we have learned about improving antimicrobial activity. Clin. Infect. Dis, 33, 180-186 (2001). DOI: 10.1086/321846.

[35] B. Marquez, V. Pourcelle, C. M. Vallet, M. P. MingeotLeclercq, P. M. Tulkens, J. Marchand-Bruynaert, F. Van Bambeke, Pharmacological Characterization of 7-(4(Piperazin-1-yl)) Ciprofloxacin Derivatives: Antibacterial Activity, Cellular Accumulation, Susceptibility to Efflux Transporters, and Intracellular Activity, Pharm. Res, 31, 1290-1301 (2014). DOI: 10.1007/s11095-013-1250-x.

[36] F. L. Alovero, X. S. Pan, J. E. Morris, R. H. Manzo, L. M. Fisher, Engineering the specificity of antibacterial fluoroquinolones: benzenesulfonamide modifications at C-7 of ciprofloxacin change its primary target in Streptococcus pneumoniae from topoisomerase IV to gyrase, Antimicrob. Agents. and Chemother, 44, 320325 (2000). DOI: 10.1128/AAC.44.2.320-325.2000.

[37] R. Beyer, E. Pestova, J. J. Millichap, G. A. Noskin, L. Peterson, A convenient assay for estimating the possible involvement of efflux of fluoroquinolones by Streptococcus pneumoniae and Staphylococcus aureus: evidence for diminished moxifloxacin, sparfloxacin, and trovafloxacin efflux, Antimicrob. Agents Chemother, 44, 798-801 (2000). DOI: 10.1128/AAC.44.3.798.

[38] Gergely Völgyi, Gábor Vizserálek, Krisztina TakácsNovák, Alex Avdeef, Kin Y. Tam, Predicting the exposure and antibacterial activity of fluoroquinolones based on physicochemical properties, Eur. J. Pharm. Sci, 47, 21-27 (2012). DOI: 10.1016/j.ejps.2012.04.022.

[39] T. Takenouchi, F. Tabata, Y. Iwata, H. Hanzawa, M. Sugawara, S. Ohya, Hydrophilicity of Quinolones Is Not an Exclusive Factor for Decreased Activity in effluxmediated resistant mutants of Staphylococcus aureus, Antimicrob. Agents Chemother, 40, 1835-1842 (1996).

[40] L. V. Piddock, M. M. Johnson, Accumulation of 10 fluoroquinolones by wild-type or efflux mutant Streptococcus pneumoniae, Antimicrob. Agents Chemother, 46, 813820 (2002). DOI: 10.1128/AAC.46.3.813-820.2002.

[41] J. L. Vazquez, S. Merino, O. Domeinech, M. Berlanga, M. Vinas, M. T. Montero, J. Hernandez.-Borrell, Determination of the partition coefficients of a homologous series of ciprofloxacin: influence of $\mathrm{N}-4$ piperazinyl alkylation on antimicrobial activity, Int. $J$. Pharm, 220: 53-62 (2001). DOI:10.1016/S0378-5173(01)00646-9.

[42] A. Dalhoff, F. J. Schmitz, In vitro antibacterial activity and pharmacodynamics of new quinolones. Eur. J. Clin. Microbiol, 22, 203-221 (2003). 
